\title{
Interdecadal changes in synoptic transient eddy activity over the Northeast Pacific and their role in tropospheric Arctic amplification
}

\author{
Dong Xiao ${ }^{1,2} \cdot$ Hongli Ren ${ }^{1,2}$
}

Received: 27 September 2020 / Accepted: 26 March 2021 / Published online: 3 April 2021

(c) The Author(s) 2021

\begin{abstract}
Arctic amplification refers to the greater surface warming of the Arctic than of other regions during recent decades. A similar phenomenon occurs in the troposphere and is termed "tropospheric Arctic amplification" (TAA). The poleward eddy heat flux and eddy moisture flux are critical to Arctic warming. In this study, we investigate the synoptic transient eddy activity over the North Pacific associated with TAA and its relationship with the subtropical jet stream, and propose the following mechanism. A poleward shift of the subtropical jet axis results in anomalies of the meridional gradient of zonal wind over the North Pacific, which drive a meridional dipole pattern of synoptic transient wave intensity over the North Pacific, referred to as the North Pacific Synoptic Transient wave intensity Dipole (NPSTD). The NPSTD index underwent an interdecadal shift in the late 1990s accompanying that of the subtropical jet stream. During the positive phase of the NPSTD index, synoptic eddy heat flux transports more heat to the Arctic Circle, and the eddy heat flux diverges, increasing Arctic temperature. This mechanism highlights the need to consider synoptic transient eddy activity over the North Pacific as the link between the mean state of the North Pacific subtropical upper jet and TAA.
\end{abstract}

Keywords Synoptic transient eddy activity $\cdot$ Tropospheric Arctic amplification · Subtropical upper jet stream · Eddy heat flux

\section{Introduction}

Warming of the Arctic near-surface air temperature has been a clear feature of global warming in recent decades. This warming is occurring two to three times faster than the global average, a phenomenon referred to as Arctic amplification. In addition to surface warming, the Arctic has shown significant warming throughout the troposphere (Cohen et al. 2020), and this is termed "Tropospheric Arctic amplification" (TAA). Arctic amplification occurs in all seasons but is more robust in autumn and winter (Cohen et al. 2014). Numerous mechanisms have been proposed to

Dong Xiao

xiaodong@cma.gov.cn

1 State Key Laboratory of Severe Weather, Chinese Academy of Meteorological Sciences, Beijing 100081, People's Republic of China

2 Institute of Tibetan Plateau and Polar Meteorology, Chinese Academy of Meteorological Sciences, Beijing 100081, People's Republic of China explain Arctic amplification during the past two decades. Surface Arctic warming has long been considered as a response of anthropogenic climate change owing to its consistency with the warming in coupled model simulations of projections forced by increasing greenhouse gas concentrations (Holland and Bitz 2003). The rapid loss of Arctic sea ice under the radiative effects of greenhouse gas forcing has led to greater absorption of solar shortwave radiation and greater emission of heat from open waters, and results in surface Arctic warming (Dai et al. 2019; Screen and Simmonds 2010; Screen et al. 2012; Wu et al. 2015). Other mechanisms include the feedback of Eurasian snow cover and Arctic albedo in the cryosphere (Cohen et al. 2013, 2014), tropical SST forcing (Ding et al. 2014), reductions in air pollution over Europe (Acosta Navarro et al. 2016), changes in mineral-dust aerosols (Lambert et al. 2013), shifts in Arctic vegetation (Pearson et al. 2013), changes in Arctic clouds and water vapor content (Ghatak and Miller 2013; Graversen and Wang 2009; Laîné et al. 2016), a smaller increase in Arctic upward longwave radiation than at middle and lower latitudes (Pithan and Mauritsen 2014), anomalies of Ural 
blocking (Chen et al. 2018; Luo et al. 2016, 2018), changes in atmospheric available potential energy (Lee 2014), and trends associated with the several phases of the Madden-Julian Oscillation (Yoo et al. 2011; 2012).

The transport of heat and moisture from middle and lower latitudes is also very important for Arctic warming. Poleward total energy transport across $60^{\circ} \mathrm{N}$ results in Arctic warming two weeks later (Graversen et al. 2008). An increase in poleward atmospheric moisture transport is the dominant factor in the enhancement since late 1990s of river discharge over the Eurasian Arctic (Zhang et al. 2013). The enhancement of poleward moisture transport since 2002 from the North Pacific induces a significant increase in specific humidity in the Arctic Pacific sector, which is accompanied by an increase in downward longwave radiation and contributes to sea-ice area decrease and Arctic warming (Lee et al. 2017). The Atlantic sector along $0-80^{\circ} \mathrm{E}$ transports major fluxes of sensible and latent heat below $750 \mathrm{hPa}$ into the $70^{\circ}-90^{\circ} \mathrm{N}$ Arctic region (Alekseev et al. 2019). This influx explains more than $50 \%$ of the average temperature variability over the Arctic in wintertime. However, the transport of heat and moisture by the atmospheric circulation associated with atmospheric waves varies differently on both temporal and spatial scales. Fan et al. (2015) identified an increase trend in the transient eddy flux of energy over Greenland and the Greenland Sea during 1979-2012. Over that same period, enhancement of transient eddy activity (extracted by a temporal filter) appeared over North Canada, the Greenland Sea, and the Norwegian Sea, while activity decreased over west-central Siberia. Graversen and Burtu (2016) suggested that planetary waves contribute more to Arctic surface temperatures than do synoptic-scale stationary waves (the waves being extracted by Fourier transforms over longitude and height). However, the contribution of synoptic transient waves to tropospheric Arctic warming (17.8 K per year) between 20 Century Coupled Climate Model (20C3M) and A1B scenario simulations is much larger than that of stationary waves $(-3.4 \mathrm{~K}$ per year) (Kug et al. 2010). Changes in the Arctic Oscillation pattern are consistent with the change in synoptic transient eddy feedback. A poleward shift of the jet stream and storm tracks can make the synoptic eddy feedback more effective over high latitudes, which in turn enhances the poleward shift of the Arctic Oscillation mode (Choi et al. 2010). Low-frequency North Atlantic Oscillation-related flow can induce synoptic eddy heat feedback on potential temperature anomalies in the troposphere (Zhao et al. 2020). Although there are some differences in the conclusions of these studies, it is clear that mid-latitude synoptic transient wave activity plays an important role in Arctic warming.

Meandering of the mid-latitude jet stream is widely debated as a means by which Arctic warming influences mid-latitude weather and climate (Barnes and Screen 2015).
The hypothesis is that Arctic amplification decreases the meridional temperature difference between the Arctic and middle latitudes, and then induces a weaker, slower, or more sinuous mid-latitude jet stream, which then influences midlatitude extreme weather (Francis and Vavrus 2012). Butler et al. (2010) argued that Arctic warming in a dry dynamical core model can induce weaker poleward eddy momentum flux, stronger zonal-mean zonal wind along $30^{\circ}-40^{\circ} \mathrm{N}$, and weaker zonal wind to the south and north. Several studies also demonstrated that a weaker polar frontal jet stream and stronger subtropical upper jet stream can be caused by changes in Arctic sea ice in coupled models (Blackport and Kushner 2016; Deser et al. 2015; Sun et al. 2015). However, Meleshko et al. (2016) showed that changes in Arctic sea ice can induce a weaker polar frontal jet stream but cannot increase the strength of the subtropical jet stream. However, global warming in simulations can enhance the subtropical upper jet stream and weaken the polar frontal jet stream. All of the changes in the polar frontal and subtropical jet stream in the above models are smaller than their internal variability. Although some argument existing, most of the above facts demonstrated that the Arctic warming or Arctic sea ice loss imposed important influence on the intensity and location of subtropical jet and frontal jet. Besides the Arctic, El Niño-Southern Oscillation (ENSO), as the most striking climate signals, have strong impacts on the intensity and locations of upper subtropical jet (Yang and Webster 1990). Meridional displacement of summer upper subtropical jet is related to the tropical Middle and East Pacific SST through the meridional teleconnection influenced by the convection over the Northwest Pacific (Lin and Lu 2009). However, the East Asian winter jet cores does not strongly relate to the ENSO (Yang et al. 2000). The upper tropospheric climate signals caused by ENSO's are over the tropics and North Pacific east of the dateline (Yang et al. 2002). A joint effect of a positive phase of the Atlantic Multi-decadal Oscillation and a negative phase of the Interdecadal Pacific Oscillation since the late 1990s has enhanced the meridional temperature gradient and the Eady growth rate and thus increased Asian zonal wind between the two jets, but weakened them to the south and north of the jet axes, thereby devoting to the poleward and equatorward shifts of the East Asian subtropical Jet and frontal jet, respectively (Huang et al. 2019).

In contrast, changes in the location and intensity of the subtropical upper jet stream can induce changes in the meridional gradient of zonal wind. As one component of relative vorticity, changes in the meridional gradient of zonal wind $(\partial u / \partial y)$ cause anomalous development and meridional propagation of eddy vorticity. The variation of East Asian jet stream is closely related to synoptic transient eddy activity (Ren et al. 2008; Xiang and Yang 2012; Xiao and Zhang 2015; Xue and Zhang 2017; Zhang and Chen 2017). The synoptic eddy activities can transport more heat and 
moisture under a A1B scenario simulation, which favors enhanced Arctic warming and moistening (Kug et al. 2010). It is therefore of importance to investigate whether mid-latitude synoptic transient eddy activity is related to changes in the subtropical upper jet stream and favor Arctic warming in reanalysis data.

In this study, we investigate changes of the relationship between synoptic transient wave activity and tropospheric Arctic temperature between a normal and warming Arctic troposphere, defined a dipole index of transient wave intensity, which is related to the changes of background of tropospheric Arctic temperature, and explore its relationship with the northern subtropical upper jet over the North Pacific and contribution to tropospheric Arctic warming. Our study highlights the role of synoptic transient wave activity in the influence of a meridional shift of the subtropical upper jet on tropospheric Arctic warming during the wintertime. The rest of this paper is organized as follows. Section 2 describes data and methodology. We defined the Tropospheric Artic Amplification (TAA) index in Sect. 3. In Sect. 4, we show the changes of the relationship between tropospheric Arctic air temperature and synoptic transient wave activity during different background state of the TAA index, and define a North Pacific synoptic transient wave intensity dipole (NPSTD) index to represent synoptic transient wave activity over the North Pacific. In Sect. 5, the physical meaning of the NPSTD index and its possible drivers are investigated. The contribution of the NPSTD index to TAA is presented in Sect. 6. In Sect. 7, we combine these results to propose a hypothesis about the causes of the NPSTD index and its effects on tropospheric Arctic warming. A summary and discussion are provided in Sect. 8.

\section{Data and methodology}

We obtained data for air temperature, the zonal, meridional, and vertical components of wind velocity from the European Centre for Medium-Range Weather Forecasts (ECMWF)Interim Reanalysis (ERA-Interim; http://apps.ecmwf.int/ datasets/; Dee et al. 2011). These are 6-hourly, global, gridded data at a resolution of $1.5^{\circ} \times 1.5^{\circ}$ for the period from January 1979 to August 2019. We use ERA-Interim rather than ECMWF 40-year Reanalysis (ERA-40) because although both reanalyses produce surface air temperature and humidity trends that agree with observation, the polar tropospheric air-temperature trends in ERA-40 disagree with trends from radiosonde and satellite observations owing to observation-system and time-dependent errors (Bitz and Fu 2008). These problems have been resolved in ERA-Interim, and both polar surface and tropospheric temperature trends agree with radiosonde and satellite observations (Dee et al. 2011). Daily mean variables were calculated by removing the 40 year climatological mean for each day (except for 29 February, which was calculated by removing the 10 year climatological mean of leap years during the period) and each grid point. This study focuses on the main Arctic warming season (boreal winter; December-January-February: DJF). Winter averages were calculated using the mean of daily averages.

For this study, we extracted the 2.5-6 day synoptic variability from the daily wind velocity $\left(u^{\prime}, v^{\prime}\right.$ and $\left.w^{\prime}\right)$ and air temperature $\left(T^{\prime}\right)$ using a Lanczos filter (Duchon 1979). Transient wave activity is noticeable in the middle and upper troposphere and is centered at the $300 \mathrm{hPa}$ level. We identified filtered $v^{\prime 2}$ at $300 \mathrm{hPa}$ to indicate the intensity of synoptic transient wave activity. The eddy kinetic energy of the synoptic transient waves is defined as $\left(u^{\prime 2}+v^{\prime 2}\right) / 2$, and large values of eddy kinetic energy represent the active domain of transient waves. The eddy heat flux is represented by $u^{\prime} T^{\prime}, v^{\prime} T^{\prime}$ and $w^{\prime} T^{\prime}$ in the zonal, meridional and vertical directions, respectively. The meridional eddy vorticity flux is defined as $v^{\prime}\left(\partial v^{\prime} / \partial x-\partial u^{\prime} / \partial y\right)$. The horizontal divergence of synoptic eddy flux can enhance the basic flow (Chen et al. 2003; Kug et al. 2010; Xiao and Zhang 2015), and we focus on the divergence of the eddy heat flux to indicate the positive contribution of synoptic transient eddy activity to Arctic mean temperature.

The Eliassen-Palm (E-P) flux is widely applied to indicate the flux of stationary or quasigeostrophic eddy activity and the eddy forcing of the basic flow (Chen et al. 2003; Plumb 1985, 1986; Takaya and Nakamura 2001). The local E-P flux $\left(\mathrm{E}_{\mathrm{u}}\right)$ proposed by Trenberth (1986) effectively depicts the horizontal vector flux of localized transient eddy activity and its forcing on the mean flow (Chen et al. 2012):

$\mathrm{E}_{\mathrm{u}}=\left[\frac{1}{2}\left(v^{\prime 2}-u^{\prime 2}\right),-u^{\prime} v^{\prime}\right]$

$\mathrm{E}_{\mathrm{u}}$ is used in this study to show the horizontal distribution of transient wave activity flux. The divergence of this flux $\left(\nabla \cdot \mathrm{E}_{\mathrm{u}}\right)$, which is identical in form to the E-P flux in the zonal-mean case, provides the main localized forcing of the time-mean zonal flow by the transient eddies.

Linear regression and correlation describe the relationship between two factors. Significance testing of the regression and correlation coefficients is based on a two-tailed Student's $t$ test, which accounts for temporal auto-correlation using an effective sample size. Significance is reported at the 95\% confidence level, unless stated otherwise.

\section{Definition of the TAA index}

A winter warming trend that has led to an increase of more than $0.2 \mathrm{~K}$ per decade over the past 40 years (1979-2018), at the surface and in the troposphere, is evident in the Arctic 
Circle at the 95\% confidence level (Fig. 1a). The surface of the Arctic experienced the greatest warming over this period $(>4 \mathrm{~K})$. The tropospheric Arctic temperature show significant warming trend at $1000-300 \mathrm{hPa}$ with the warming spread of approximate $0.8-4 \mathrm{~K}$ per 40 years. There are also larger warming trends over the Arctic from 300 to $100 \mathrm{hPa}$ but these do not exceed the $95 \%$ confidence level. The warming trend over the northern subtropics in the troposphere and tropical upper troposphere also exceeds $0.2{ }^{\circ} \mathrm{C}$ per decade in the troposphere at the $95 \%$ confidence level. Warming of both the tropical upper troposphere and Arctic troposphere has the effect of a tug-of-war on the jet stream, and has also been observed over the past four decades.

Arctic amplification refers to that the surface Arctic has warmed as twice as faster than the global surface average since late-1990s. As seen in Fig. 1a, this phenomenon also exist in the troposphere. We compared the tropospheric Arctic temperature (averaged over 1000-300 hPa, $60^{\circ}-90^{\circ} \mathrm{N}$ ) and global troposphere temperature (averaged over $1000-300 \mathrm{hPa}, 90^{\circ} \mathrm{S}-90^{\circ} \mathrm{N}$ ). It can be seen that the anomalies of tropospheric Arctic temperature is twice larger than that of global tropospheric temperature. Therefore, we defined this phenomenon as Tropospheric Arctic Amplification (TAA) and employed the anomalies of tropospheric Arctic temperature (averaged over $1000-300 \mathrm{hPa}, 60^{\circ}-90^{\circ}$ $\mathrm{N}$, red box in Fig. 1a) as the TAA index.

Tropospheric global temperature anomalies (averaged over $1000-300 \mathrm{hPa}, 90^{\circ} \mathrm{S}-90^{\circ} \mathrm{N}$ ) shows a gradually increasing trend over the past 40 years with a value of $\sim 0.5^{\circ} \mathrm{C}$ at the end of the period (Fig. 1b). The 9 year running mean of the TAA (solid red line, Fig. 1b) is higher than that at middle and lower latitudes between 1979 and 1987, but lower between 1988 and 1997, and warmed more rapidly from the late 1990s onwards to reach $\sim 1.0^{\circ} \mathrm{C}$ by the end of the study period, twice the increase seen at global average. Generally, the TAA index can be considered as having a long-term trend and also can be divided into two different background states before and after late-1990s. We employed a moving t-test technique (Xiao and Li 2007) with a detecting scale of 10 years to examine the decadal changes of the mean
Fig. 1 a Trends of DJF zonally averaged temperature from 1000 to $100 \mathrm{hPa}$ (K per decade), $\mathbf{b}$ DJF temperature anomalies from 1000 to $300 \mathrm{hPa}$ over $90^{\circ} \mathrm{S}-90^{\circ} \mathrm{N}$ (blue line) and $60^{\circ}-$ $90^{\circ} \mathrm{N}$ (red box in a, red line) (compared with their means over the period 1979-1998) and the 9-year running means (thickened solid line for red and blue lines, respectively). The black thickened solid line denotes the episode averages (1979-1999 and 2000-2018) of the TAA index. The change point of the mean value of the TAA index is the year of 1999 , which is detected by the moving t-test technique. The TAA index is defined as the temperature anomaly in the red box. Stippling in the upper panel indicates the $95 \%$ confidence level
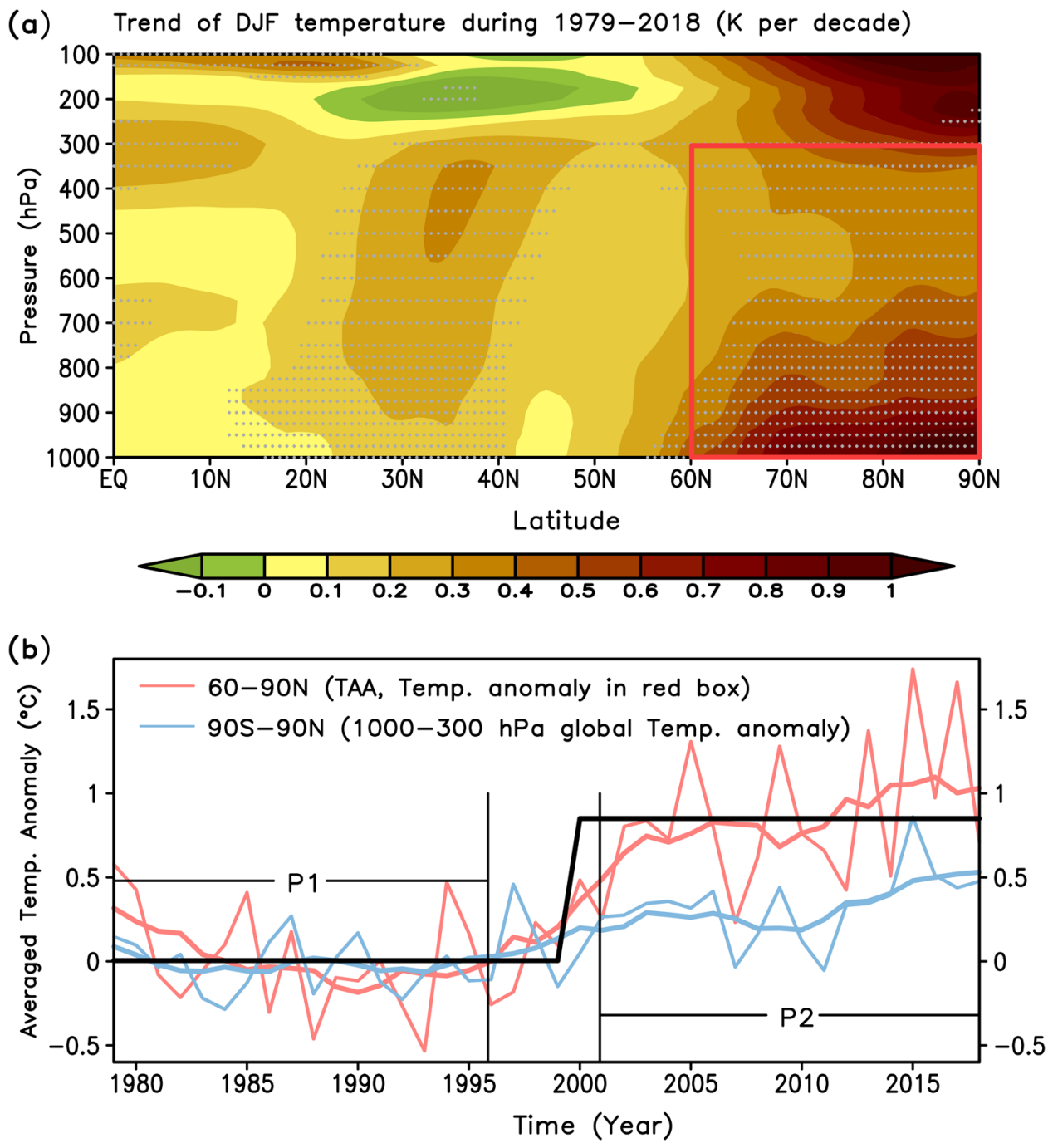
value of the TAA index. The decadal change year of the man value of the TAA index is the year of 1999 (definition of the decadal change year refers to that in Xiao and Li 2007). Although a long-term trend in the TAA index throughout the study period (1979-2018), there is no significant trend (exceeding the $95 \%$ confidence level) of TAA index in these periods (1979-1999, 2000-2018, P1 and P2). The mean value during $2000-2018$ is $0.85 \mathrm{~K}$ significantly higher than that during 1979-1999, at the $99 \%$ confidence level, which suggests that the TAA index since 1979 can also be divided into two different background state. Therefore, we, according to Figs. 1b, 2d, selected common 18 years for two periods in this study: a lull period (1979-1996; P1) and an warming period (2001-2018; P2).

\section{Changes of the relationship between the TAA and synoptic transient wave activity}

Figure 2 presents transient wave intensity separately regressed on the daily normalized TAA index in P1 and P2 and their difference. During P1, the transient wave intensity anomalies associated with daily normalized TAA index
Fig. 2 Transient wave intensity regressed on the normalized TAA during a P1, b P2, and c the difference between $\mathbf{a}$ and b. The units in a-c are $\mathrm{m}^{2} \mathrm{~s}^{-2}$. The stippling in $\mathbf{a}$ and $\mathbf{b}$ denotes the $95 \%$ confidence level. d DJF averaged (solid black line) and episode averaged (solid blue line) NPSTD index. The episode of mean value of the NPSTD index is divided by the moving t-test technique at the $95 \%$ confidence level. The change point of mean value of the NPSTD index occurred at the year of 1996. The NPSTD index is defined as the normalized difference of normalized transient wave intensity between the blue box and the green box (blue box minus green box)

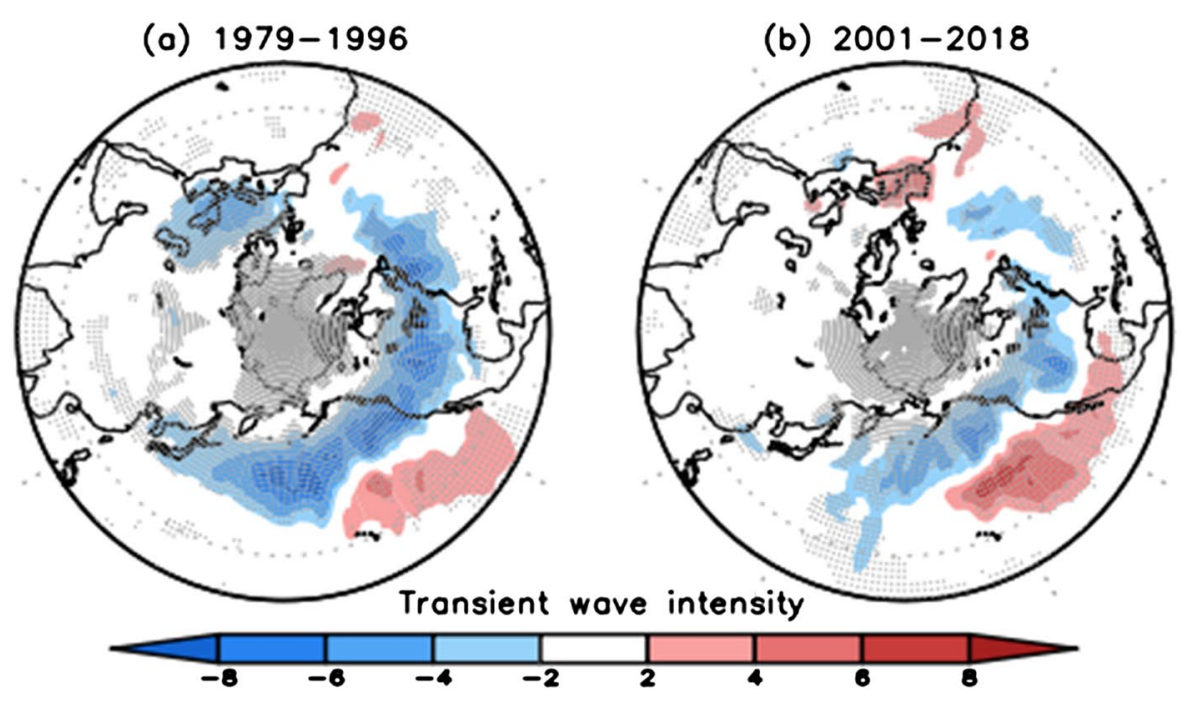

(c) 2001-2018 minus 1979-1996

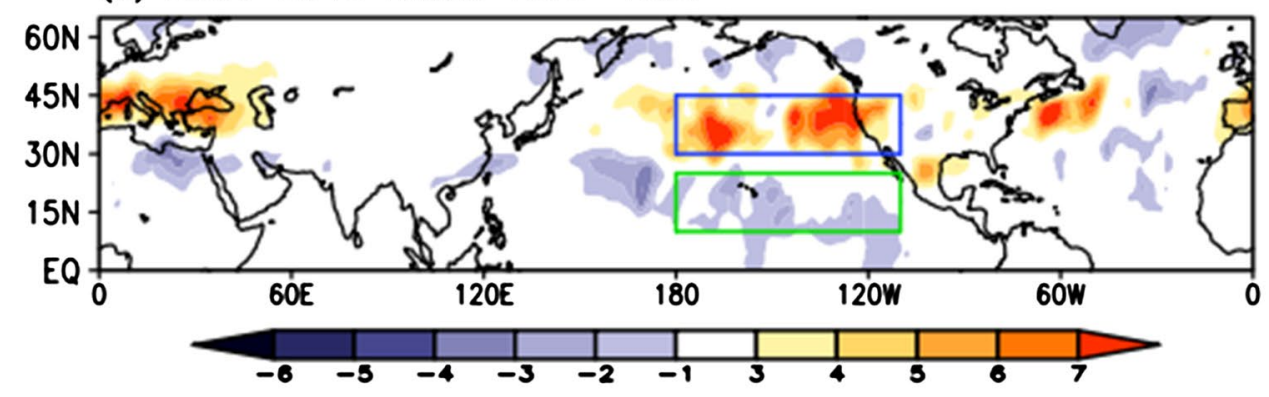

(d) DJF NPSTD index

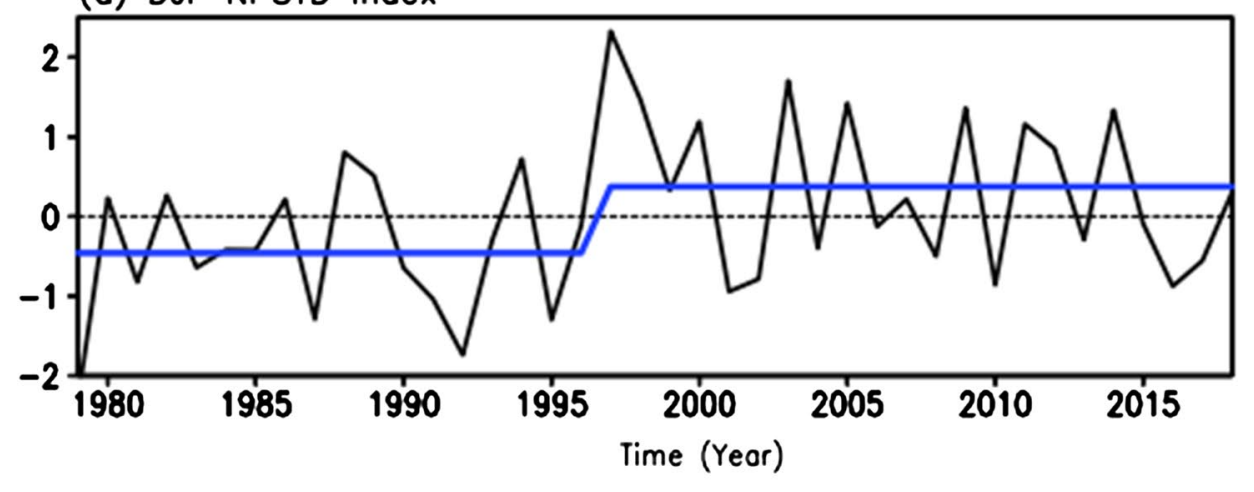


display significant positive anomalies over the southeastern North Pacific and significant negative anomalies over Europe and the middle latitudes from $120^{\circ} \mathrm{E}$ to $30^{\circ} \mathrm{W}$ (Fig. 2a). The regression of transient wave intensity on daily normalized TAA index in P2 shows a similar pattern to that of Fig. 2a (Fig. 2b). However, the negative transient wave intensity anomalies weaken and retreat back to the sub-polar regions by about $5^{\circ}$ of latitude, and the center of positive transient wave intensity anomalies, with larger anomalies, moves northward to the middle latitudes of the eastern Pacific and North America. A significant positive center also emerges over southeastern Europe. The relationship and its change between detrended TAA and transient wave intensity are highly similar to these in Fig. 2a, b. Therefore, the trend during P1 and P2 of TAA and transient wave intensity does not dominant their relationship and its change. Due to that the transient wave intensity is the square of 2.5-6 days filtered meridional wind, we can conclude that the relationship between the TAA index and transient wave intensity in P1 and $\mathrm{P} 2$ are mainly on synoptic time scales.

A comparison of Fig. $2 b$ with Fig. 2 a shows positive differences of regression coefficient over the middle and eastern North Pacific, western North Atlantic, and South Europe, and negative differences over the northern and southern North Pacific, the North Atlantic, and Northeast Africa (Fig. 2c). This pattern suggests that those regions with larger differences of regression coefficient are closely linked to changes of the background state of TAA. The domain with the largest and strongest difference of regression coefficient in Fig. 2c is over the North Pacific, which is a key region to understand the Arctic warming and downstream weather and climate. On the one hand, the broken ridge of Rossby wave over the northern North Pacific transports warmer air to the Arctic and favors Arctic warming (Miyakoda et al. 1983). On the other hand, the synoptic eddies over the northeastern Pacific are important to the development of Pacific blocking, which has a significant impact on extreme weather over North America (Carrera et al. 2004; Nakamura and Wallace 1993). Therefore, we define the North Pacific synoptic transient wave intensity dipole (NPSTD) index as the normalized difference obtained by subtracting the normalized transient wave intensity anomalies over the southeastern North Pacific $\left(110^{\circ}-180^{\circ} \mathrm{W}, 7.5^{\circ}-22.5^{\circ} \mathrm{N}\right.$; green box in Fig. $\left.2 \mathrm{c}\right)$ from those over the central North Pacific $\left(110^{\circ}-180^{\circ} \mathrm{W}, 30^{\circ}-45^{\circ}\right.$ $\mathrm{N}$; blue box in Fig. 2c). There is also a similar meridional pattern over South Europe and Northeast Africa. We define a Europe-Northeast Africa synoptic transient wave intensity dipole index by subtracting the normalized transient wave intensity anomalies over Northeast Africa $\left(10^{\circ}-50^{\circ}\right.$ $\left.\mathrm{E}, 22^{\circ}-32^{\circ} \mathrm{N}\right)$ from those over Europe $\left(0^{\circ}-60^{\circ} \mathrm{E}, 37^{\circ}-50^{\circ}\right.$ $\mathrm{N})$. There are no significant contemporaneous or lead-lag correlations between the Europe-Northeast Africa synoptic transient wave intensity dipole and NPSTD indices. The effects of the Europe-Northeast Africa dipole index are not considered in this study. The NPSTD index, a dimensionless index, was in a generally negative phase over the period P1, and in a positive phase from 1997 onwards. The standard deviations of the NPSTD index during P1 and P2 are 0.83 and 0.89 , respectively. There is no significant difference in the variance in the NPSTD index between P1 and P2. However, the NPSTD index experienced a significant interdecadal change of mean value in late-1990s. The mean value of NPSTD index changed from -0.3 during 1979-1996 to 0.46 during 1997-2018, at the $95 \%$ confidence level. Similar to the TAA index, there is no significant trend of NPSTD index in P1 and P2, respectively. This suggests that an interdecadal regime shift of the NPSTD index occurred during the late 1990s accompanied with the change of background state of the TAA index.

\section{Meaning of the NPSTD index and its relationship to the subtropical jet stream}

\subsection{Meaning of the NPSTD index}

Figure 3 a shows that there are two centers of climatological 300-hPa transient wave intensity, over the Northeast Pacific and Northwest Atlantic (contours), which correspond to centers of synoptic transient eddy activity. The correlation between the daily NPSTD index and 300-hPa transient wave intensity is positive over the Northeast Pacific and western and central United States and negative over the subtropical Central Pacific. This implies that when the daily NPSTD index is positive, the synoptic transient eddy activity over the Northeast (subtropical Central) Pacific is stronger (weaker) than normal. Therefore, the NPSTD index represents a meridional pattern of stronger synoptic eddy activity over the Northeast Pacific and weaker activity around the Hawaiian Islands.

The significant anomalies of Eu divergence associated with the daily NPSTD index are positive over the North Pacific and northern Central Pacific, and negative over the subtropical North Pacific and Alaska, which implies that the source of the transient wave activity associated with the NPSTD index lies over the North Pacific (Fig. 3b). These anomalies show a meridional structure of interaction between the NPSTD index and mean flow. When the NPSTD index is positive, the synoptic transient eddy activity accelerates the mean flow over the North Pacific and northern tropical Central Pacific and decelerates the mean flow over the subtropical North Pacific and Alaska. The negative and positive centers of $\mathrm{Eu}$ divergence also appear alternately over the regions from the North Pacific to West Europe, which suggests that the Rossby waves associated with the 
Fig. 3 a Climatology of 300$\mathrm{hPa}$ transient wave intensity (contours) and its correlation coefficient with the daily NPSTD index (shading). Regression on the daily NPSTD index of b local Eliassen-Palm flux (vector) and its divergence (shading) and $\mathbf{c}$ meridional eddy vorticity flux (shading) and eddy kinetic energy (contours). Stippling in all panels represents the $95 \%$ confidence level. Green vectors in b indicate the $95 \%$ confidence level. Only contours exceeding the $95 \%$ confidence level are drawn in blue in c. The units are indicated for each variable in each panel (a) 300-hPa transient wave intensity $\left(\mathrm{m}^{2} \mathrm{~s}^{-2}\right)$ and correlation with NPSTD
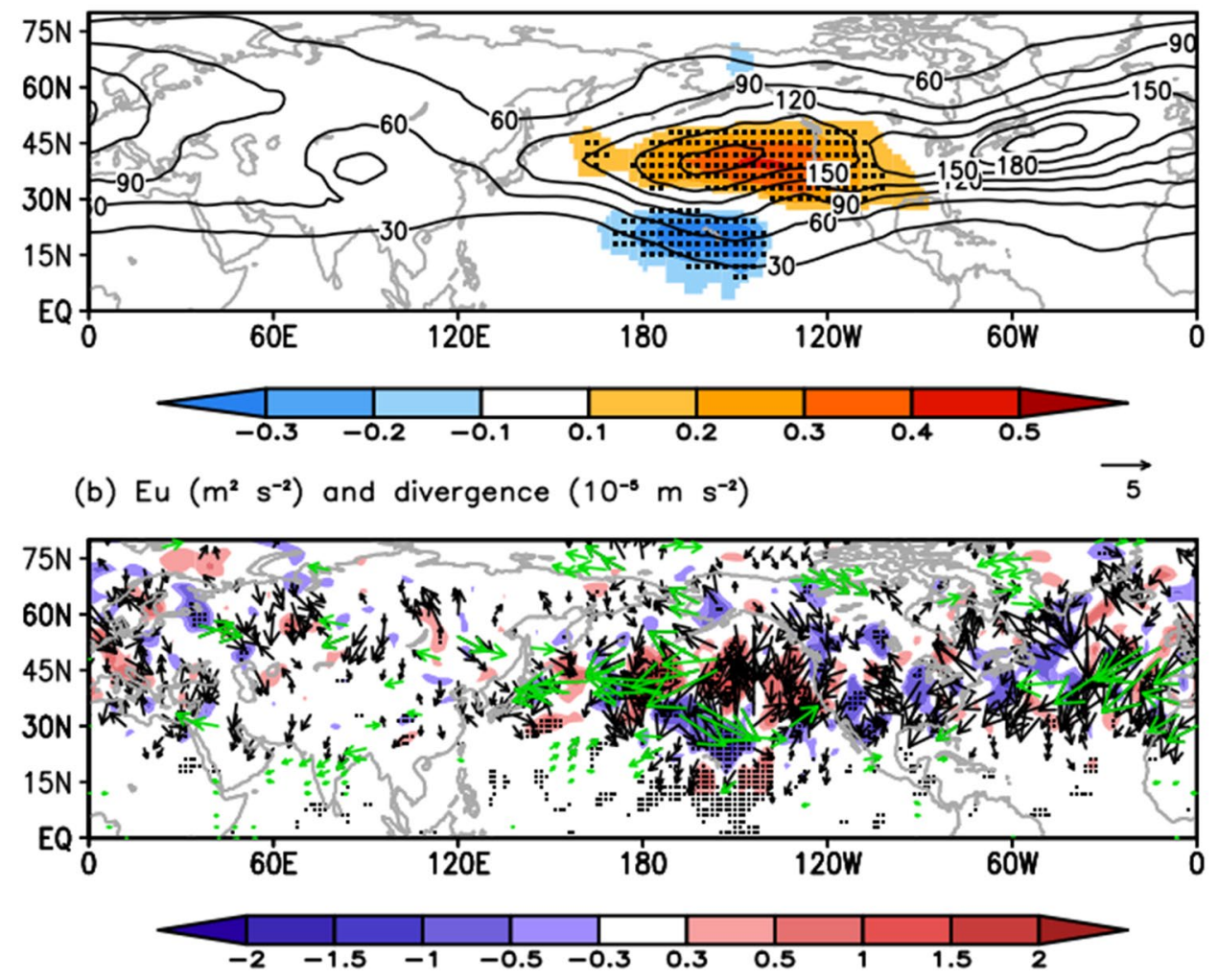

(c) Meridional vorticity flux $\left(10^{-s} \mathrm{~m} \mathrm{~s}^{-2}\right)$ and eddy kinetic energy $\left(\mathrm{m}^{2} \mathrm{~s}^{-2}\right)$

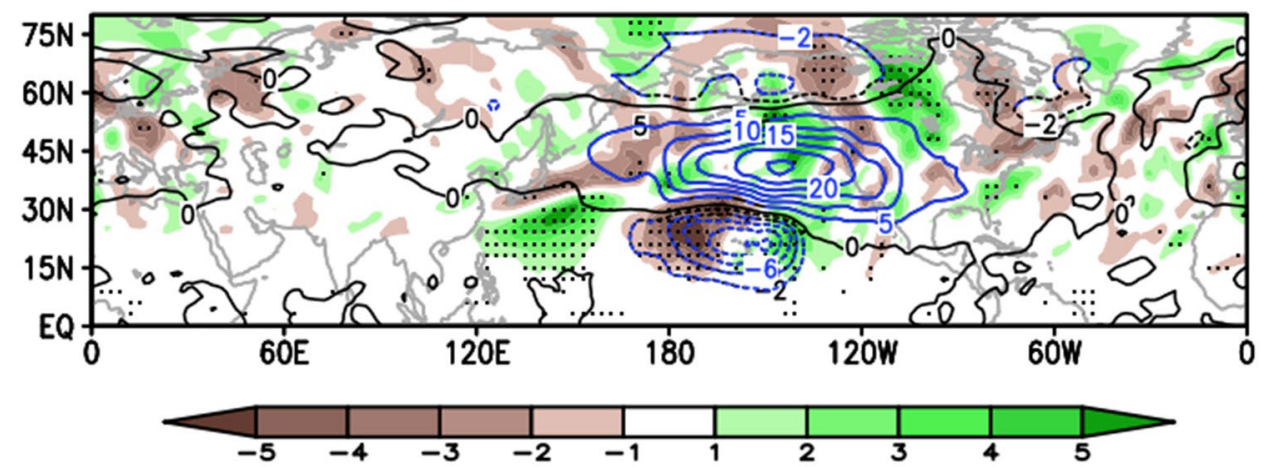

NPSTD index propagates from the North Pacific to West Europe accompanied by interaction with the mean flow.

The eddy kinetic energy regressed on the daily NPSTD index also displays a meridional pattern, with significant positive anomalies over the North Pacific and Middle North America, centered on the Northeast Pacific with a maximum value of $35 \mathrm{~m}^{2} \mathrm{~s}^{-2}$; negative anomalies are found surrounding the Hawaiian Islands, reaching $-10 \mathrm{~m}^{2} \mathrm{~s}^{-2}$, and over the regions from the Anadyr Plateau to Northwest Canada (Fig. 3c). These observations suggest that when the NPSTD index is positive, the eddy kinetic energy is higher over the North Pacific and thus the synoptic transient eddies are more active there. Likewise, lower eddy kinetic energy appears over the regions surrounding the Hawaiian Islands and Alaska, which means less active synoptic transient eddies there. Figure $3 \mathrm{c}$ shows that the meridional vorticity flux anomalies associated with the daily NPSTD index are negative to the west of the Hawaiian Islands, over the Northwest Pacific, West and East Canada, central North Atlantic, and West Europe, which denotes southward transport of vorticity, and positive over the subtropical West Pacific, Northeast Pacific, Central Canada, and South Greenland, which represents poleward transport of vorticity, consistent with the findings of Fan (2012). These anomalies of meridional vorticity from the North Pacific to the Arctic Ocean and the North Atlantic Ocean; this supports the idea that synoptic 
transient wave activity associated with the NPSTD index occurs over the Western Hemisphere. Therefore, we focus on the effects of the NPSTD index on temperature in the Western Hemisphere.

\subsection{Relationship between the NPSTD index and the subtropical jet stream}

Figure $4 \mathrm{a}$ displays daily NPSTD-related relative vorticity anomalies, which emerge over the middle and high latitudes from the North Pacific to the North Atlantic. They appear to alternating positive and negative meridional vorticity anomalies over the Northwest Pacific, Northeast Asia and the Sidi islands, over the eastern North Pacific, over Middle and North America, and over the North Atlantic and South Greenland, respectively. Of note, three opposite centers over the North Pacific and North America lie along the subtropical jet axis, which suggests that the relative vorticity associated with the NPSTD index may be related to variations in the subtropical jet stream.

Therefore, we checked the relationship between the daily NPSTD index and the $300-\mathrm{hPa}$ zonal wind. The $300-\mathrm{hPa}$ zonal wind regressed on the daily NPSTD index shows three belts with negative anomalies over the regions from North
Fig. 4 Regression on the NPSTD index of 300-hPa a relative vorticity, b zonal wind, and $\mathbf{c} \partial u / \partial y$. The contour in $\mathbf{b}$ is climatological mean of zonal winds (1979-2018). The units are indicated for each variable in each panel. Stippling in all panels represents the $95 \%$ confidence level. The thicken black dashed lines in a and c denote the location of the jet axis during 1979-1996 (only zonal wind exceeding $30 \mathrm{~m} \mathrm{~s}^{-1}$ is drawn) (a) $300-\mathrm{hPa}$ relative vorticity $\left(10^{-6} \mathrm{~s}^{-1}\right)$

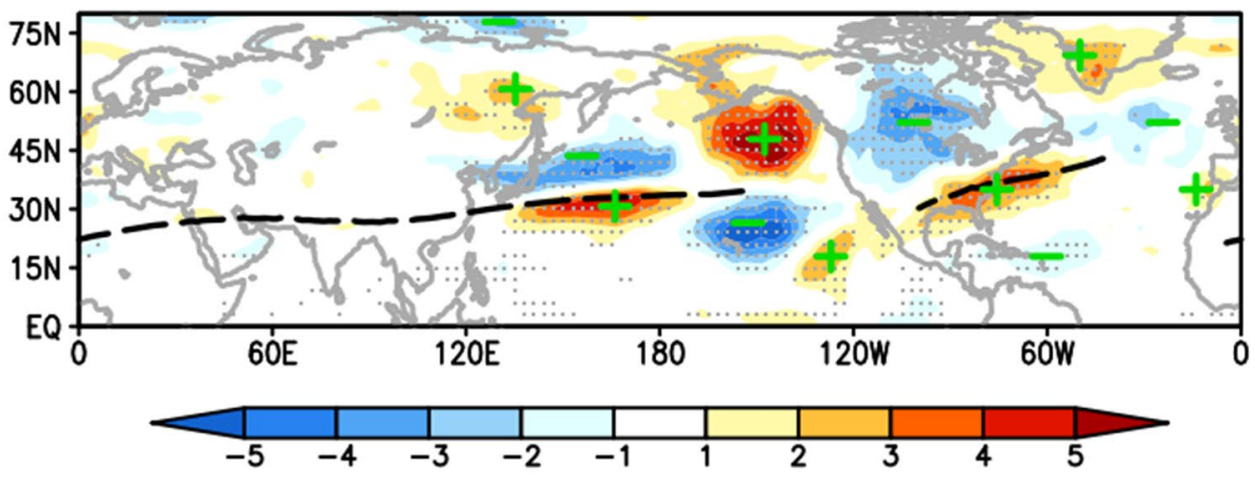

(b) 300-hPa zonal wind $\left(\mathrm{m} \mathrm{s}^{-1}\right)$

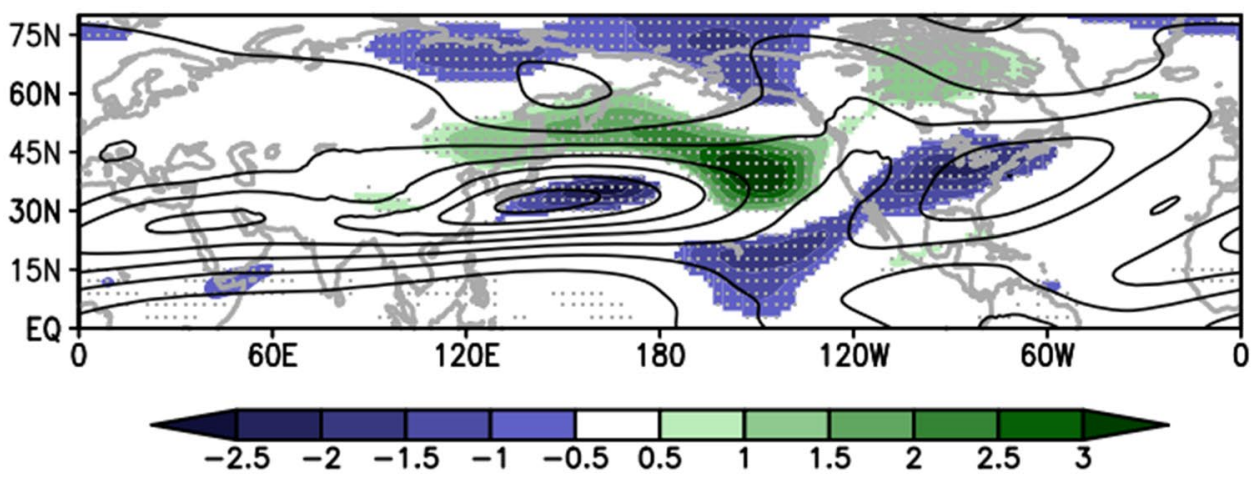

(c) $300-\mathrm{hPa}-\delta \mathrm{u} / \mathrm{dy} \quad\left(10^{-6} \mathrm{~s}^{-1}\right)$

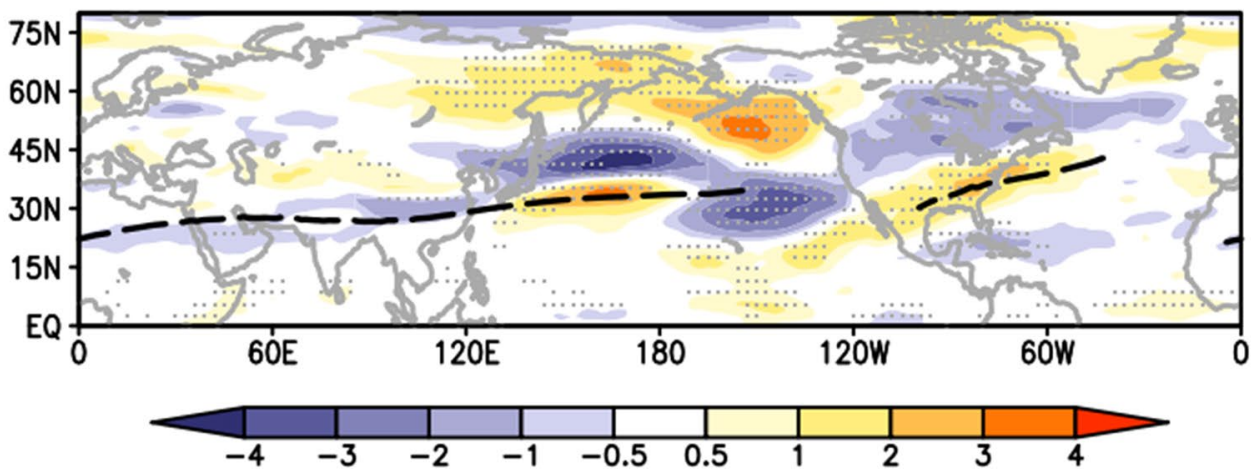


Siberia to Alaska and from the subtropical Northwest Pacific to the United States and positive anomalies from the North Pacific to Northeast Canada (Fig. 4b). When the NPSTD index is positive, the zonal wind in the northern subtropical jet over the northern North Pacific and Northeast Canada is stronger than normal, whereas the zonal wind speed is weaker to the south of the subtropical jet center, over the sub-polar regions from Siberia to Alaska, and over the tropical Central Pacific and United States. The centers of 300-hPa zonal wind anomalies related to the daily NPSTD index are shifted northward relative to the centers of relative vorticity anomalies in Fig. 4a and do not overlap with them. Given that the eddy relative vorticity is the sum of two terms, $-\partial u^{\prime} / \partial y$ and $\partial v^{\prime} / \partial x$, and that the NPSTD index is a meridional pattern of transient wave intensity, which means that a weak zonal gradient of meridional wind is associated with the NPSTD index, it is speculated that the vorticity anomalies associated with the NPSTD index may be closely linked with the meridional gradient of zonal winds $\left(-\partial u^{\prime} / \partial y\right)$. We further present the anomalies of 300-hPa $-\partial u^{\prime} / \partial y$ regressed on the daily NPSTD index (Fig. 4c). The locations of these anomaly centers correspond closely to those of relative vorticity regressed on the NPSTD index. These results suggest that the eddy relative vorticity associated with the NPSTD index may be closely linked with the meridional gradient of zonal wind. This in turn suggests that the NPSTD pattern may be caused by the variation in the meridional gradient of zonal winds.

To identify the cause of subtropical jet axis during different backgrounds, Fig. 5a shows the climatology of 300-hPa DJF mean zonal wind and its difference between P1 and P2. The 300-hPa DJF mean zonal wind during 1979-2018 is characterized by a belt with stronger zonal wind, the subtropical jet stream. There are two dominant modes of subtropical upper jet stream along $60^{\circ}-160^{\circ} \mathrm{E}$ (Xiao et al. 2016). The first mode is a symmetrical change along the subtropical jet axis, accounting for $40.2 \%$ of the explained variance, corresponding to intensity variations of the subtropical jet stream. The second mode, accounting for $28.2 \%$ of the explained variance, shows opposite changes along the subtropical jet axis, and denotes a sideways shift of the subtropical jet axis toward to the side with positive anomalies of zonal winds (Fig. 2 in their study). A slight meridional swing of the subtropical jet axis induces obvious changes in zonal winds to its north and south in the climatology (Zhang and Huang 2011). Figure 5a shows that the interdecadal changes in $300-\mathrm{hPa}$ zonal winds display positive anomalies over the northern part of the subtropical jet stream from Africa to the North Pacific, over the tropical Middle Pacific, and over the center of the North Atlantic subtropical jet, and negative anomalies over the southern part of the subtropical jet stream from Africa to the North Pacific and over the
Fig. 5 Composite difference (shading) in DJF mean 300-hPa a zonal wind and $\mathbf{b} \partial u / \partial y$ between the periods 2001-2018 (P2) and 1979-1996 (P1). Their climatological values (contours) during 1979-1996 (P1) are shown in each panel. Gray squares in both panels represent the $95 \%$ confidence level. The units are indicated in each panel. The thicken black dashed and solid green lines denote the location of the jet axis (only zonal wind exceeding $30 \mathrm{~m} \mathrm{~s}^{-1}$ is drawn) during 2001-2018 (P2) and 1979-1996 (P1), respectively

\section{(a) DJF zonal wind at $300 \mathrm{hPa}\left(\mathrm{m} \mathrm{s}^{-1}\right)$}

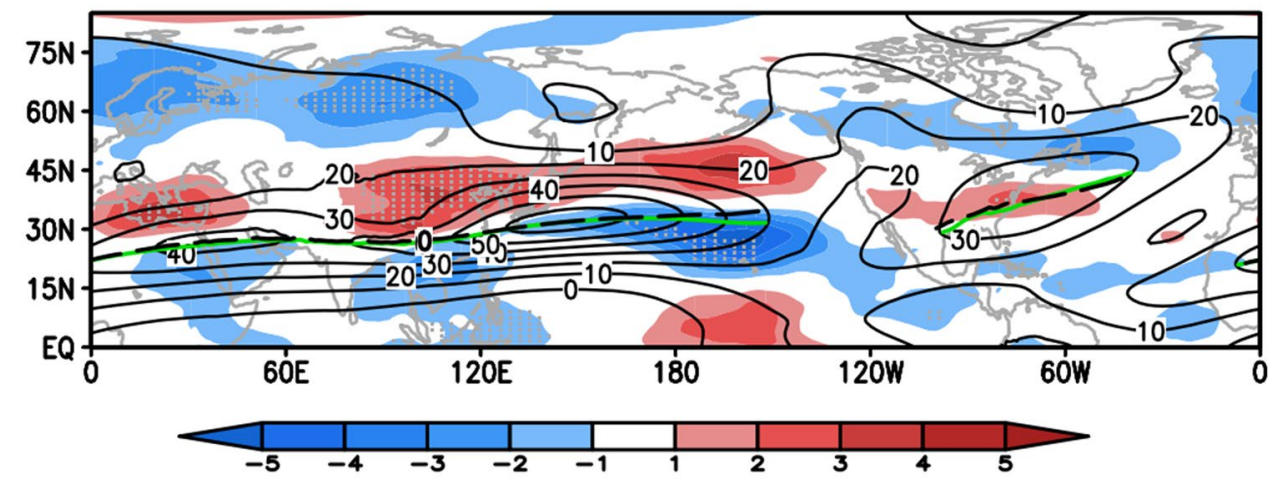

(b) DJF du/dy at $300 \mathrm{hPa}\left(10^{-6} \mathrm{~s}^{-1}\right)$

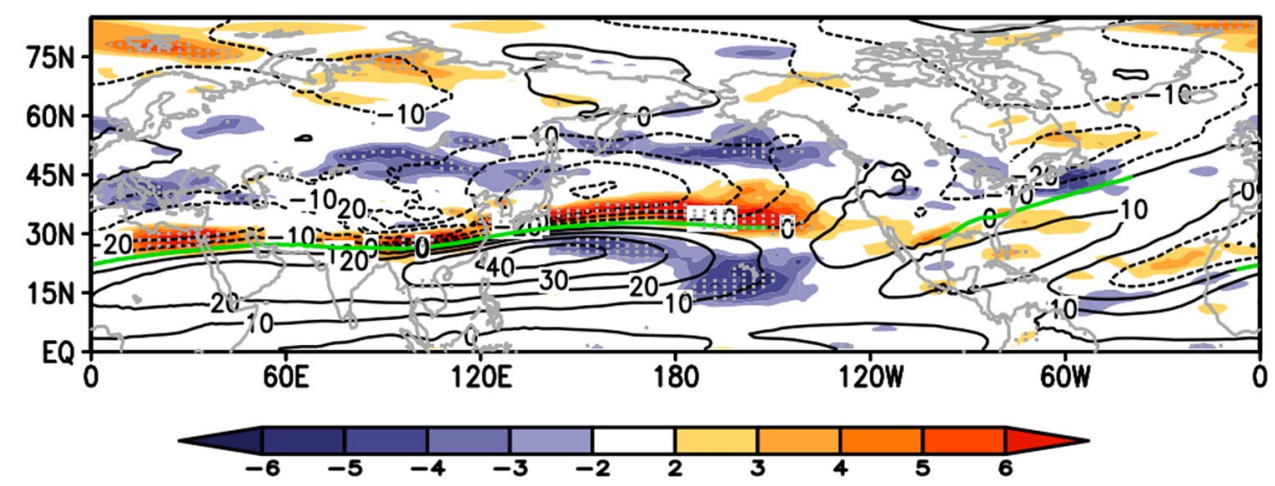


sub-polar region from northern North America to Siberia. These changes in 300-hPa zonal winds imply an interdecadal poleward shift of the northern subtropical jet axis and a weaker sub-polar upper jet stream. There is a slight poleward shift of the subtropical jet axis over the Middle East and East Asia and a more obvious one over the North Pacific, which is accompanied by positive and negative anomalous zonal winds to the north and south of the shifts of the subtropical jet axis (Fig. 5a). The largest poleward shift of the northern subtropical jet axis is over the eastern North Pacific, with a northward shift of approximately $3^{\circ}$ latitude, equal to $333 \mathrm{~km}$. Figure S1 shows a latitude-height cross averaged zonal wind between 2001-2018 and 1979-1996. The interdecadal changes in the zonal winds show positive anomalies over the middle latitudes in the middle and high troposphere and negative anomalies over the lower latitudes of the troposphere. The interdecadal shift of the zonally averaged subtropical jet axis is about $\sim 0.5^{\circ}$ poleward, equal to $\sim 56 \mathrm{~km}$, at the middle and high levels. Therefore, the northward shift of $3^{\circ}$ latitude of the subtropical upper jet axis over the eastern North Pacific is a very large change of the northern subtropical jet axis in the climatological field.

The meridional gradient of zonal wind naturally responds to the interdecadal changes in zonal wind. Interdecadal changes in the meridional gradient of 300-hPa DJF mean zonal wind (Fig. 5b) are characterized by a long belt with a significant positive gradient change to the north of the subtropical upper jet axis from Africa to the North Pacific. There are also negative anomalies along $50^{\circ} \mathrm{N}$ from Middle Asia to the North Pacific and to the south of the subtropical upper jet axis over the North Pacific, which is the region with the largest northward shift of the subtropical jet axis.
These anomalies form a significant meridional triple pattern over the North Pacific, located at the interface between the anomalous centers of zonal winds in Fig. 5a. Such a pattern accelerates the relative vorticity over the southern and northern North Pacific and decelerates that over the subtropical North Pacific, which corresponds closely to the pattern of relative vorticity associated with the NPSTD index in Fig. 4c. The change of monthly-mean zonal wind is positively correlated with the anomalous meridional eddyvorticity by synoptic eddy activity, which is demonstrated by both diagnosis reanalysis and present climate models (Kug and Jin 2009; Kug et al. 2010). Accompanied with the meridional poleward propagation of eddy-vorticity, synoptic eddy-vorticity formed anomalous meridional Rossby wave, similar to that in Fig. 4c. This suggests that the poleward shift of the period-mean subtropical upper jet axis over the North Pacific may be one of important origin of the NPSTD pattern.

To check the relationship between meridional displacement of subtropical Jet stream and Arctic temperature, we, according to Lin and $\mathrm{Lu}$ (2005), defined a daily North Pacific subtropical Jet Meridional Displacement index (NPJMD) by subtracting the zonal wind over the south North Pacific $\left(170^{\circ} \mathrm{E}-140^{\circ} \mathrm{W}, 20^{\circ}-35^{\circ} \mathrm{N}\right)$ from those over the central North Pacific $\left(170^{\circ} \mathrm{E}-140^{\circ} \mathrm{W}, 35^{\circ}-50^{\circ}\right.$ $\mathrm{N})$. The leading and lagged correlations in Fig. 6 show that the NPJMD (NPSTD) leads 10 (6) days to the $60^{\circ} \mathrm{N}$ poleward 300-hPa Arctic temperature over the Western Hemisphere. The above results suggest a temporal relationship that the NPJMD is in advance of NPSTD, which leads to the 300-hPa Arctic temperature over Western Hemispheric. This relationship is very interesting. We

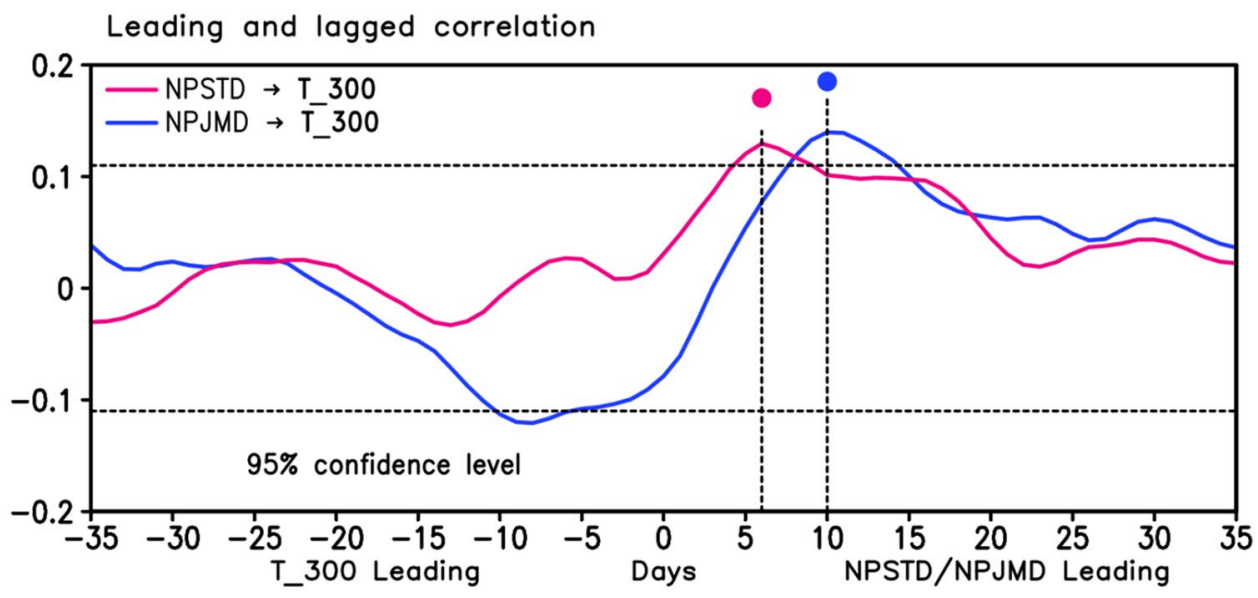

Fig. 6 Leading and lagged correlation of detrended 300-hPa Arctic air temperature over the Western Hemisphere and detrended NPSTD (pink solid line) and NPJMD (blue solid line). T_300 denote the $60^{\circ} \mathrm{N}$ poleward of Arctic air temperature at $300 \mathrm{hPa}$ over the Western Hemisphere. The positive (negative) abscissa denotes the NPSTD and NPJMD leading to (lagged) T_300. Horizontal dashed lines refer to the $95 \%$ confidence levels. Vertical dashed lines indicate the peaks of the correlation coefficient of NPSTD and NPJMD with the Arctic air temperature, which is corresponding to the days leading to the Arctic air temperature. The original time series shows the same relationship among them 
will focus on the case analysis of this relationship in further study. Such relationship suggests that the meridional displacement of subtropical jet may cause the anomaly of the NPSTD index, and thereby contribute to the Arctic warming. These relationship among them are robust with the original (including the trend) time series of these variables (figure not shown). That means the interdecadal poleward shift of subtropical jet may also cause the interdecadal changes of the NPSTD index, thereby contribute the background change of TAA index.

\section{Contribution of the NPSTD index to TAA}

In Fig. 7a, the eddy heat flux associated with the daily NPSTD index zonally averaged over the Western Hemisphere during P1 shows significant southward eddy heat transport at lower latitudes in both the troposphere and stratosphere, with the largest anomalies of southward eddy heat flux occurring along $40^{\circ} \mathrm{N}$ in the troposphere. There is a belt with significant southward eddy heat flux anomalies crossing latitude $60^{\circ} \mathrm{N}$ in the upper troposphere. In this section, we focus on the contribution of eddy heat flux to the region poleward of $60^{\circ} \mathrm{N}$, which is instrumental to Arctic warming.
Fig. 7 Latitude-height cross of western-hemispheric averaged eddy heat flux (vectors in left panels; units: $\mathrm{K} \mathrm{m} \mathrm{s}^{-1}$ ) and integrals over $1000-300 \mathrm{hPa}$ (thicken green lines in right panels; units: $\mathrm{K} \mathrm{m} \mathrm{s}^{-1}$ ) and 1000-10 hPa (thicken red lines in right panels; units: $\mathrm{K} \mathrm{m} \mathrm{s}^{-1}$ ) of meridional eddy heat flux regressed on daily NPSTD index during a 1979-1996, b 2001-2018, and $\mathbf{c}$ their difference. Shading in $\mathbf{a}$ and $\mathbf{b}$ indicates the $95 \%$ confidence level of eddy heat flux. Contours in $\mathbf{c}$ indicate the difference in meridional eddy heat flux between $\mathbf{a}$ and $\mathbf{b}$ with an interval of $0.05 \mathrm{~K} \mathrm{~m} \mathrm{~s}^{-1}$. The shading in c represents the $95 \%$ confidence level of meridional eddy heat flux difference between the periods 1979-1996 and 2001-2018 (a) Eddy heat flux: 1979-1996

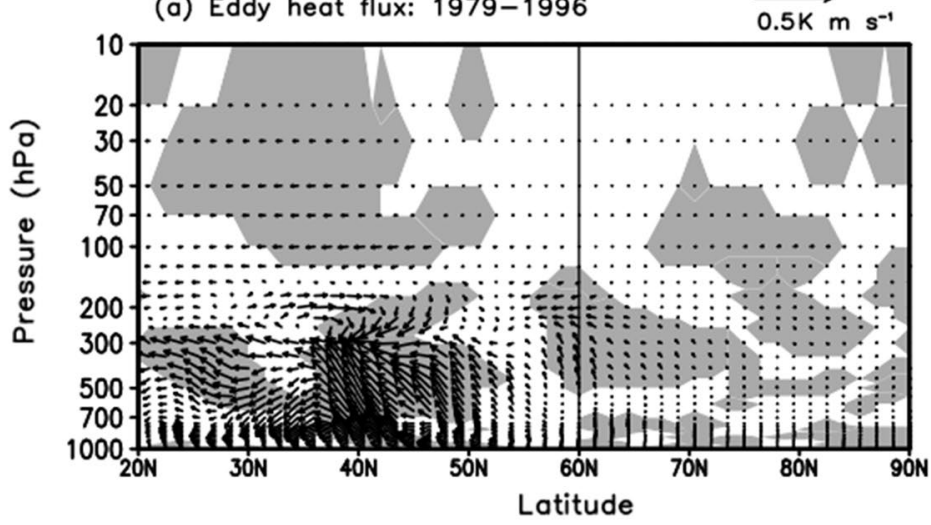

(b) Eddy heat flux: 2001-2018

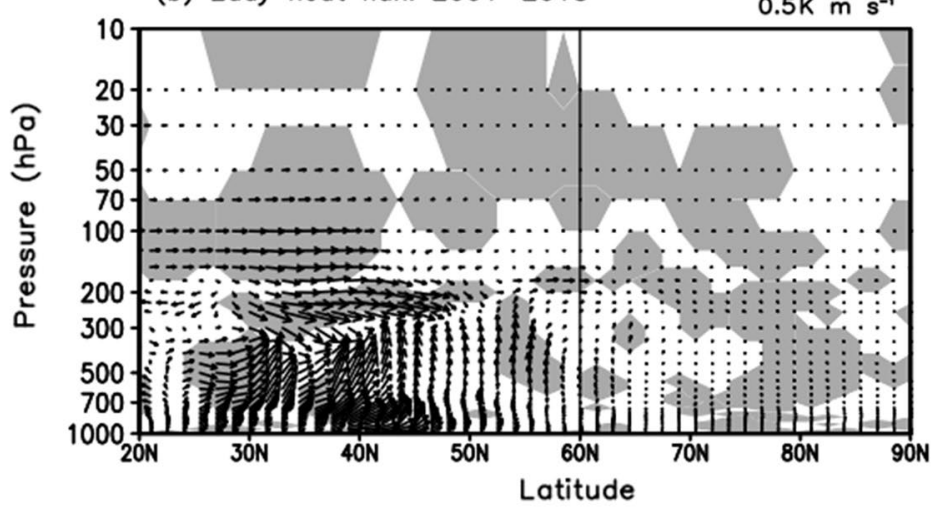

(c) (b) minus (a)

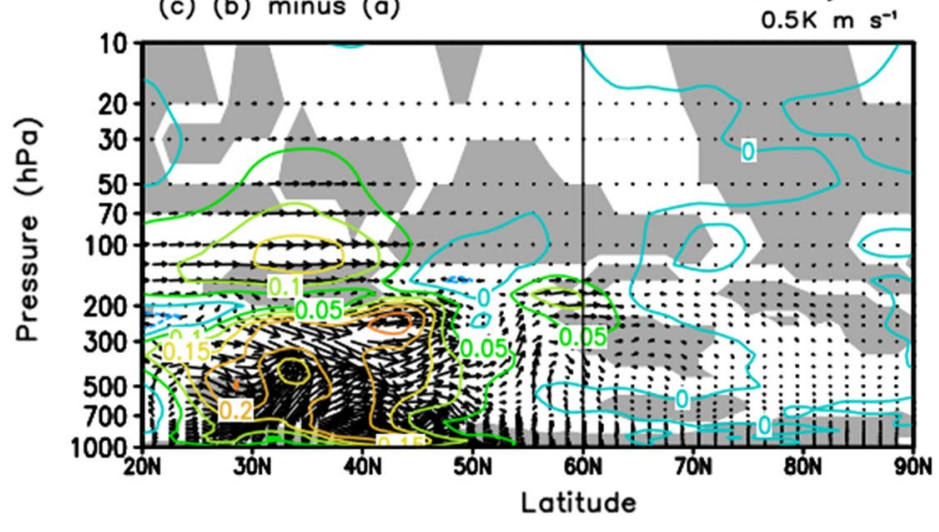

Vert. integral $\left(\times 10^{-2}\right)$

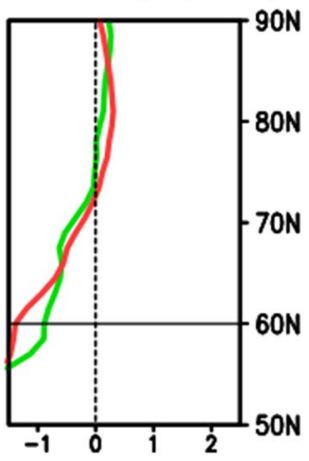

Vert. integral $\left(\times 10^{-4}\right)$

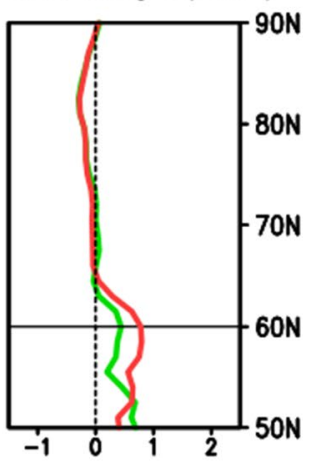

Vert. integral $\left(\times 10^{-8}\right)$

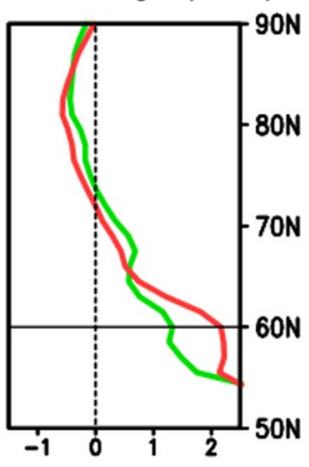


Along $60^{\circ} \mathrm{N}$ (right panel in Fig. 7a), the integral from 1000 to 300 (10) $\mathrm{hPa}$ of meridional eddy heat flux associated with the NPSTD index is $-0.9 \times 10^{-2}\left(-1.4 \times 10^{-2}\right) \mathrm{K} \mathrm{m} \mathrm{s}^{-1}$, which suggests meridional transport of heat from the polar region to lower latitudes, which is conducive to a cooler Arctic and warmer lower latitudes in both the troposphere and stratosphere. During P2 (Fig. 7b), opposite to that during $\mathrm{P} 1$, the significant eddy heat flux anomalies associated with the NPSTD index display a uniform northward transport in both the troposphere and stratosphere at middle latitudes, with the maximal anomalies being along $40^{\circ} \mathrm{N}$. Along $60^{\circ}$ $\mathrm{N}$, the eddy heat flux anomalies tend to be northward in the upper and lower troposphere and very weak southward in the middle troposphere. There is a significant belt of poleward eddy heat flux crossing $60^{\circ} \mathrm{N}$ in the stratosphere and a significant domain of upward eddy heat flux along $70^{\circ}-85^{\circ} \mathrm{N}$ in the middle and upper troposphere. The integral from 1000 to 300 (10) $\mathrm{hPa}$ of NPSTD-related meridional eddy heat flux along $60^{\circ} \mathrm{N}$ is $0.4 \times 10^{-2}\left(0.8 \times 10^{-2}\right) \mathrm{K} \mathrm{m} \mathrm{s}^{-1}$ (right panel in Fig. 7b), which indicates that the synoptic transient wave activity associated with the NPSTD index transports heat from middle latitudes to high latitudes and is instrumental in the warming of the polar region. There are also weak upward eddy heat flux anomalies at $300 \mathrm{hPa}$ along $60^{\circ}-90^{\circ}$ $\mathrm{N}$, which denotes that NPSTD-related synoptic transient waves activity transport more heat from the TAA domain (red box) to the stratosphere during P2. This result suggests that downward transport of eddy heat flux associated with the NPSTD index from the stratosphere is very weak and not key to TAA on the synoptic scale. The differences in meridional eddy heat flux between $\mathrm{P} 1$ and $\mathrm{P} 2$ display almost northward anomalies at middle latitudes (Fig. 7c). Along $60^{\circ} \mathrm{N}$, the difference in meridional eddy heat flux anomalies is positive in the troposphere and stratosphere except for weak negative anomalies at levels from 700 to $500 \mathrm{hPa}$. As a result, the difference between $\mathrm{P} 1$ and $\mathrm{P} 2$ of the integral from 1000 to 300 (10) $\mathrm{hPa}$ of the meridional eddy heat flux regressed on the NPSTD index is $1.3 \times 10^{-2}\left(2.2 \times 10^{-2}\right) \mathrm{K} \mathrm{m}$ $\mathrm{s}^{-1}$ (right panel in Fig. 7c) along $60^{\circ} \mathrm{N}$, which means a net positive tendency of northward transport of eddy heat flux by the NPSTD index during P2 compared with that during P1. Thus, the interdecadal variation in NPSTD index that occurred during the late 1990s resulted in a change (from negative to positive) in the contribution of meridional eddy heat flux to TAA.

To quantify the contribution of the NPSTD index to Arctic temperature, Fig. 8 shows the averaged divergence of the $60^{\circ} \mathrm{N}$ poleward NPSTD-related eddy heat flux in the Western Hemisphere. During P1 (Fig. 8a), the divergence of eddy heat flux had a positive tendency below $650 \mathrm{hPa}$, with

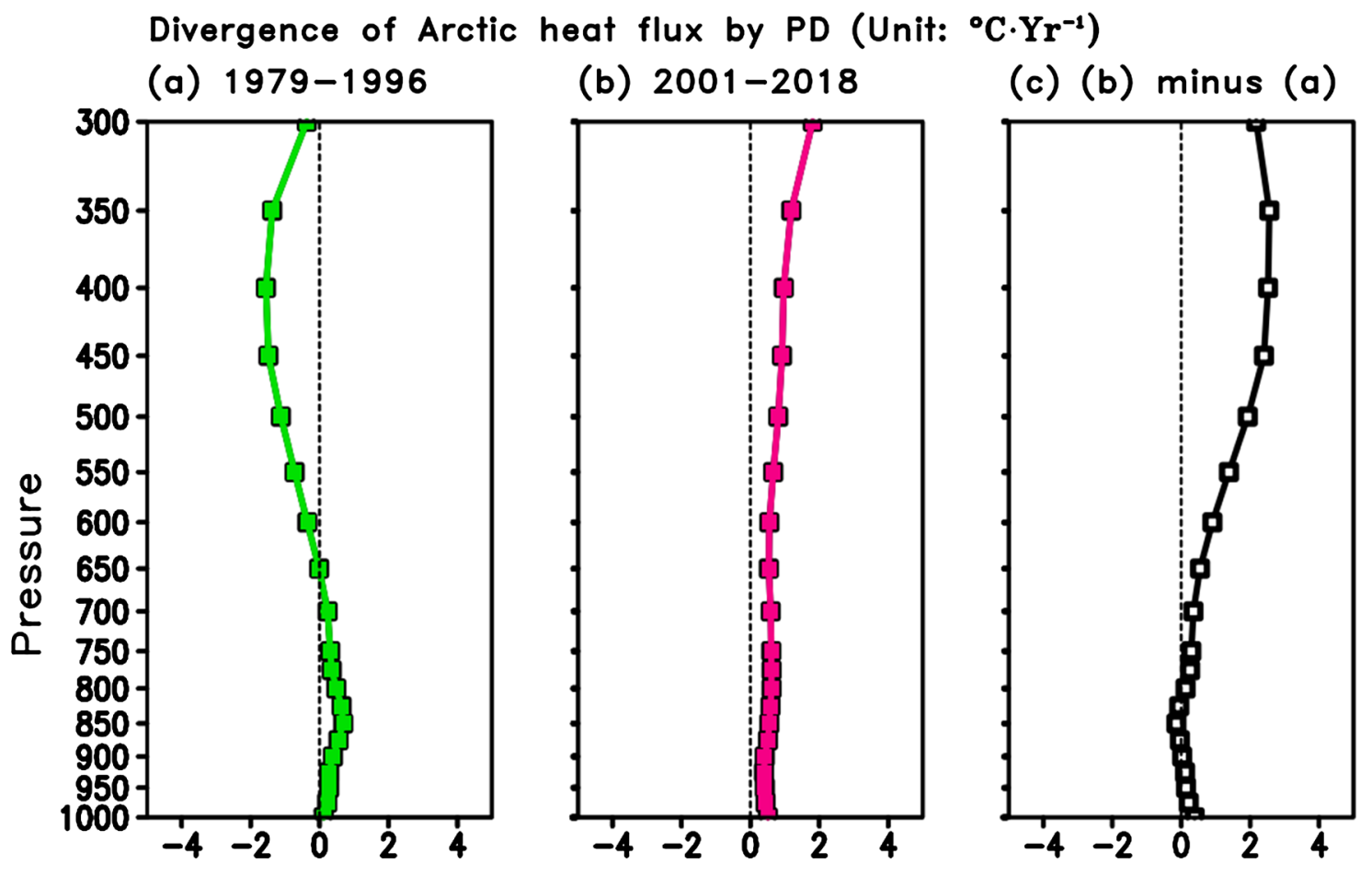

Fig. 8 Regression of the divergence of horizontal eddy heat flux on the NPSTD index over the Western Hemisphere Arctic from 1000 to $300 \mathrm{hPa}$ during a 1979-1996 (P1), b 2001-2018 (P2), and c their difference. The color lines in $\mathbf{a}$ and $\mathbf{b}$ refers to the $95 \%$ confidence level.
Positive (negative) values indicate that the synoptic transient eddy activity related to the NPSTD index rise (decline) the mean air temperature 
a maximum value of $0.6{ }^{\circ} \mathrm{C}$ year ${ }^{-1}$ and a negative tendency above $650 \mathrm{hPa}$ reaching $-1.7{ }^{\circ} \mathrm{C}$ year ${ }^{-1}$, which suggests that the synoptic transient eddy activity associated with the NPSTD index contributes to Arctic warming below $650 \mathrm{hPa}$ and that the mean temperature over the Arctic feeds the synoptic transient wave above $650 \mathrm{hPa}$. During P2 (Fig. 8b), the divergence anomalies always have a positive tendency and gradually increase from 1000 to $300 \mathrm{hPa}$, reaching $2{ }^{\circ} \mathrm{C}_{\text {year }}{ }^{-1}$ at $300 \mathrm{hPa}$. This finding implies that the eddy heat fluxes induced by the NPSTD index can contribute to the warming in the polar region during P2. The difference between P1 and P2 in the divergence of eddy heat flux associated with the NPSTD index shows minor anomalies below $700 \mathrm{hPa}$ and larger anomalies above $700 \mathrm{hPa}$, reaching a maximum value of $2.7^{\circ} \mathrm{C}_{\text {year }}{ }^{-1}$ at $350 \mathrm{hPa}$. The contribution between $\mathrm{P} 1$ and $\mathrm{P} 2$ is $2.7^{\circ} \mathrm{C}$ year ${ }^{-1}$ at $350 \mathrm{hPa}$, which is approximately equal to a warming speed of $2.7 \mathrm{~K} \mathrm{year}^{-1}$ for past 40 years and larger than the warming speed (approximately equal to $0.8-2.0 \mathrm{~K}$ per 40 years) of $350-\mathrm{hPa}$ air temperature (Fig. 1a). This means that the net tendency of eddy heat flux associated with the NPSTD index between P1 and P2 makes a positive and important contribution to the warming of the polar region, especially in the middle and upper troposphere.

\section{A possible mechanism for the effects of the NPSTD index on TAA}

Using the results described in Sects. 3-6, we propose an outline of the origin of and variation in the NPSTD index and its contribution to the TAA, as follows (Fig. 9). The interdecadal poleward shift of the subtropical jet axis over the North Pacific resulted in meridional changes of zonal wind and its associated meridional gradient over the North
Pacific and North America (Fig. 5b). As a result, a cluster of anomalous centers of eddy relative vorticity emerged over the North Pacific and North America (Fig. 4a-c), producing a meridional pattern of eddy kinetic energy anomalies, with positive anomalies appearing over the Northeast Pacific and with negative anomalies surrounding the Hawaiian Islands (Fig. 3c). The active centers of synoptic transient wave intensity over the North Pacific were moved northward and formed a meridional pattern of transient wave intensity there, namely, the NPSTD pattern (Fig. 2a-c). This pattern interacted with the mean flow and transported more eddy vorticity and eddy heat flux northward and downstream (Fig. 3b). The interdecadal northward shift of the subtropical upper jet axis over the North Pacific caused an interdecadal regime shift in the NPSTD index from the late 1990s onwards (Figs. 2d, 5a, 6). The eddy heat flux associated with the NPSTD index has a positive tendency of poleward heat transport during P2 compared with that during P1 (Fig. 7). The eddy heat flux in the Western Hemisphere over the Arctic diverged, fed the Arctic mean air temperature, and enhanced the TAA (Fig. 8).

\section{Summary and discussion}

In summary, TAA indicates rapid warming that was $2-3$ times faster than that at middle and lower latitudes from the late 1970s, with a period of much faster warming from the late 1990s onwards. Synoptic transient wave activity associated with TAA during P1 and P2 showed a poleward shift of synoptic transient wave activity center over the North Pacific, and the difference between P1 and P2 displayed a meridional dipole pattern of synoptic transient wave intensities over the North Pacific, namely, the NPSTD. The NPSTD index underwent an obvious interdecadal change and shifted
Fig. 9 Schematic showing the linkage between the subtropical upper jet stream, NPSTD, and TAA

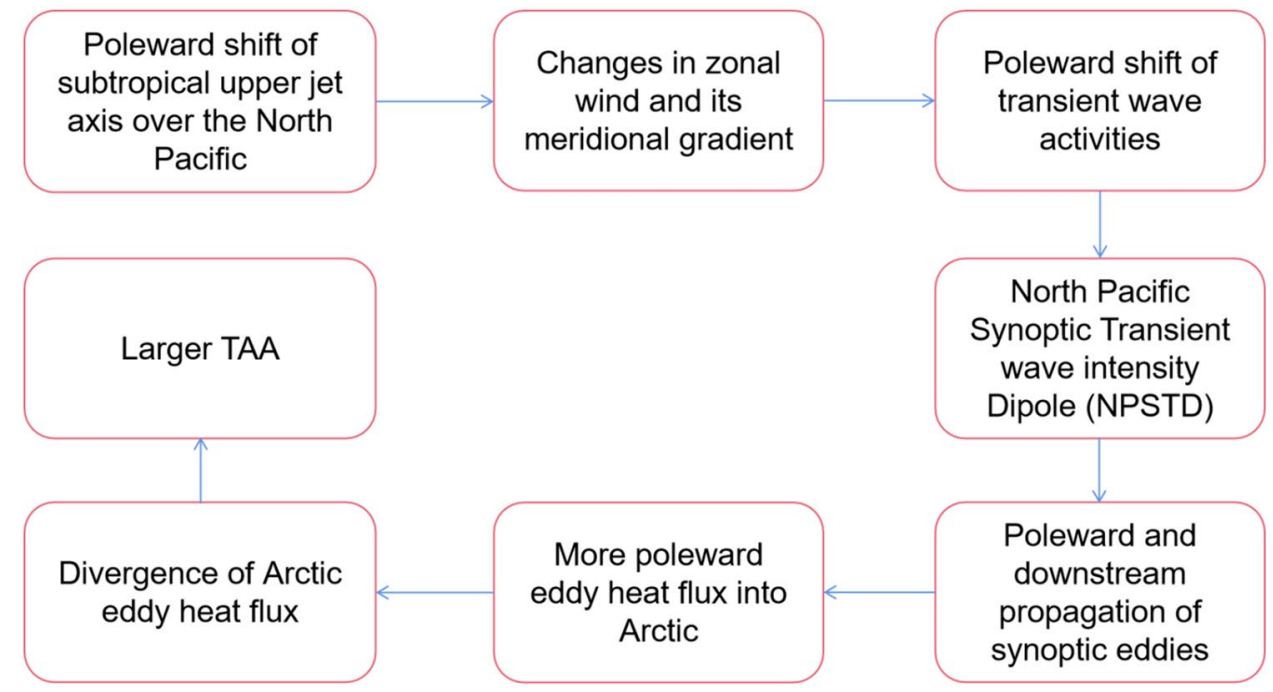


Fig. 10 Regression of vertical eddy heat flux poleward over $60^{\circ} \mathrm{N}$ at $700 \mathrm{hPa}$ and $300 \mathrm{hPa}$ on the NPSTD index. The unit is $\mathrm{K} \mathrm{m} \mathrm{s}^{-1}$. Positive values denote upward heat flux. The value is drawn on each bar. P1 (P2) represents the period 1979-1996 (2001-2018). P2 minus P1 indicates the difference between $\mathrm{P} 2$ and $\mathrm{P} 1$

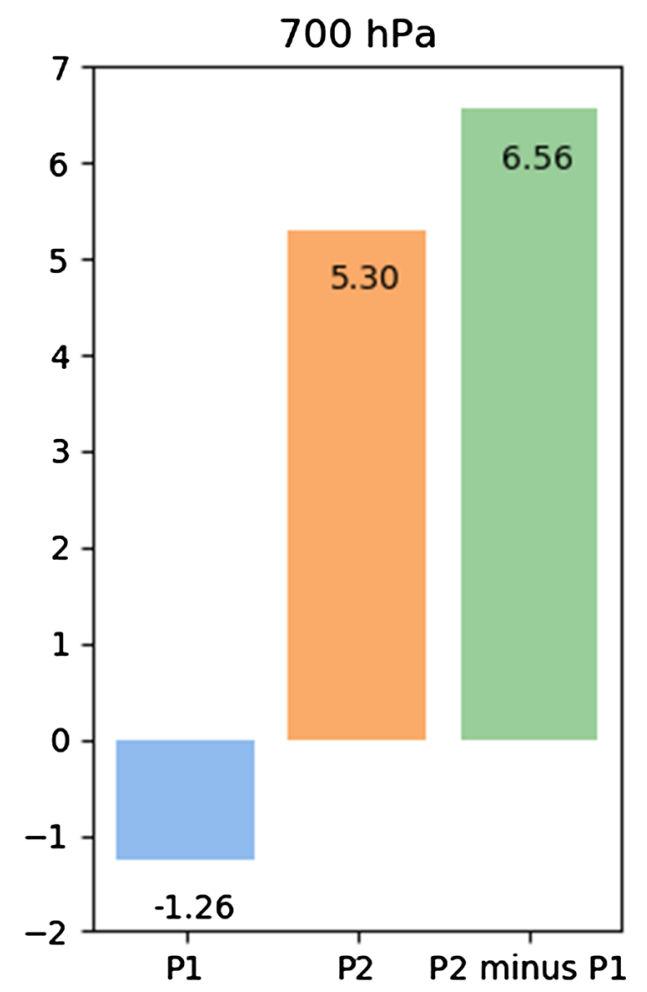

to a positive phase from the late 1990s onwards, implying more active synoptic transient waves over the Northeast Pacific since that time.

We propose a possible mechanism of TAA in which synoptic transient eddy activity is driven by the subtropical jet stream, as follows. A poleward shift of the subtropical jet axis results in stronger (weaker) zonal wind along the northern (southern) part of the jet axis. As a result, interdecadal anomalies of the meridional gradient of zonal winds over the Northeast Pacific showed a meridional triple pattern. Under this interdecadal background, a cluster of anomalies of relative vorticity and the associated meridional pattern of eddy kinetic energy emerged over the North Pacific and North America, generating a meridional dipole pattern of synoptic transient wave intensity over the Northeast Pacific, namely, the NPSTD. The meridional vorticity flux associated with the NPSTD index extended northward into the Arctic Circle and northeastward to North Canada, Greenland, and the Norway Sea. The interdecadal poleward shift of the subtropical upper jet axis resulted in interdecadal variation in the NPSTD index. This stronger NPSTD index during P2 was associated with larger poleward eddy heat flux across $60^{\circ} \mathrm{N}$. The eddy heat flux over the Arctic associated with the NPSTD index diverged at all levels of the troposphere and fed back to the mean air temperature, favoring larger TAA. This study highlights the very important role that the NPSTD index plays in the influence of the poleward shift of the subtropical upper jet axis on TAA.
The trend of middle and upper tropospheric (700-300 hPa) Arctic temperature is not as strong as in the lower troposphere and low stratosphere, giving a sandwichlike pattern. The anomalies of 700-300 hPa temperature over $60^{\circ}-90^{\circ} \mathrm{N}$, referred to its mean for $1979-1999$, reached $0.8 \mathrm{~K}$ at the end of the study period, 1.6 times that over the middle and lower latitudes (not shown). It is thus important to investigate whether the vertical transport from the lower stratosphere and lower troposphere favors warming of the middle and upper troposphere. We focused on the contribution of NPSTD-related vertical eddy heat flux at key levels. Figure 10 presents the tendency of the $700 \mathrm{hPa}$ and $300 \mathrm{hPa}$ NPSTD-related vertical eddy heat flux poleward over $60^{\circ}$ $\mathrm{N}$. The tendency is $-1.26(5.3) \mathrm{K} \mathrm{m} \mathrm{s}^{-1}$ at $700 \mathrm{hPa}$ during P1 (P2), which implies a downward (upward) transport of eddy heat flux at $700 \mathrm{hPa}$ during P1 (P2). The net increase in tendency of vertical eddy heat flux between P2 and P1 is $6.56 \mathrm{~K} \mathrm{~m} \mathrm{~s}^{-1}$, which means that NPSTD-related transient eddies transport more vertical eddy heat flux from the lower troposphere to the middle and upper troposphere during P2 relative to $\mathrm{P} 1$. At $300 \mathrm{hPa}$, the tendency is 0.03 (1.19) $\mathrm{K}$ $\mathrm{m} \mathrm{s}^{-1}$ during P1 (P2). This suggests that more eddy heat flux was transported into the lower stratosphere during P2. The net NPSTD-related vertical eddy heat flux contributes a tendency of $5.4 \mathrm{~K} \mathrm{~m} \mathrm{~s}^{-1}$ to the $700-300 \mathrm{hPa}$ temperature. This means that both the meridional and vertical eddy heat fluxes associated with the NPSTD index favor warming of 700-300 hPa troposphere. 
The ensemble mean of observed tropospheric warming trend for the average of multiple reanalyses shows a deep warming pattern with significant confidence level over the Arctic (Cohen et al. 2020); this is similar to Fig. 1a produced using ERA-Interim, indicating a robust trend of observed tropospheric air temperature. However, multimodel ensemble means of the Coupled Model Inter-comparison Project-5 (CMIP5) and Atmospheric Model Intercomparison Project show only near-surface warming over the Arctic. The difference between the observations and simulation is the warming of the middle and upper troposphere. According to the results of this study, the warming of the middle and upper troposphere is related to the transport of meridional and vertical eddy heat associated with the NPSTD index. The obvious difference between P1 and $\mathrm{P} 2$ in the contribution of horizontal synoptic NPSTDrelated eddy heat flux to Arctic warming appears in the middle and upper troposphere, whereas synoptic eddy activities transport more vertical heat flux from the lower troposphere to the middle and upper troposphere during $\mathrm{P} 2$. Besides the sparse vertical resolution in the CMIP5 models, this result suggests that the absence of a significant warming trend in the multi-model ensemble mean in the middle and upper troposphere may be related to the horizontal and vertical eddy heat flux associated with the synoptic transient eddy activity.

Supplementary Information The online version contains supplementary material available at https://doi.org/10.1007/s00382-021-05752-6.

Acknowledgements X.D. thanks two anonymous reviewers for their helpful comments and Prof. Anthony J. Broccoli for valuable assistance during a visit to Rutgers University. The authors also thank the European Centre for Medium-Range Weather Forecasts for providing the ERA-Interim reanalysis. XD was funded by the Strategic Priority Research Program of the Chinese Academy of Sciences (XDA20100300), the Second Tibetan Plateau Scientific Expedition and Research (STEP) program (2019QZKK0105), and the Basic Special Project of CAMS (2019Z008). RHL was supported by a National Science Foundation (NSF) of China grant (41775066).

Open Access This article is licensed under a Creative Commons Attribution 4.0 International License, which permits use, sharing, adaptation, distribution and reproduction in any medium or format, as long as you give appropriate credit to the original author(s) and the source, provide a link to the Creative Commons licence, and indicate if changes were made. The images or other third party material in this article are included in the article's Creative Commons licence, unless indicated otherwise in a credit line to the material. If material is not included in the article's Creative Commons licence and your intended use is not permitted by statutory regulation or exceeds the permitted use, you will need to obtain permission directly from the copyright holder. To view a copy of this licence, visit http://creativecommons.org/licenses/by/4.0/.

\section{References}

Acosta Navarro JC et al (2016) Amplification of Arctic warming by past air pollution reductions in Europe. Nat Geosci 9:277-281

Alekseev G, Kuzmina S, Bobylev L, Urazgildeeva A, Gnatiuk N (2019) Impact of atmospheric heat and moisture transport on the Arctic warming. Int J Climatol 39:3582-3592

Barnes EA, Screen JA (2015) The impact of Arctic warming on the midlatitude jet-stream: Can it? Has it? Will it? Wiley Interdiscip Rev Clim Change 6:277-286

Bitz CM, Fu Q (2008) Arctic warming aloft is data set dependent. Nature 455:E3-E4

Blackport R, Kushner PJ (2016) The transient and equilibrium climate response to rapid summertime sea ice loss in CCSM4. J Clim 29:401-417

Butler A, Thompson D, Heikes R (2010) The steady-state atmospheric circulation response to climate change-like thermal forcings in a simple general circulation model. J Clim 23:3474-3476

Carrera ML, Higgins RW, Kousky VE (2004) Downstream weather impacts associated with atmospheric blocking over the Northeast Pacific. J Clim 17:4823-4839

Chen W, Takahashi M, Graf HF (2003) Interannual variations of stationary planetary wave activity in the northern winter troposphere and stratosphere and their relations to NAM and SST. J Geophys Res Atmos 108:4797

Chen HS, Liu L, Zhu YJ (2012) Possible linkage between winter extreme low temperature events over China and synoptic-scale transient wave activity. Sci China Earth Sci 56:1266-1280

Chen X, Luo D, Feldstein SB, Lee S (2018) Impact of winter Ural blocking on Arctic sea ice: short-time variability. J Clim 31:2267-2282

Choi DH, Kug JS, Kwon WT, Jin FF, Baek HJ, Min SK (2010) Arctic Oscillation responses to greenhouse warming and role of synoptic eddy feedback. J Geophys Res 115:D17103

Cohen J, Jones J, Furtado J, Tziperman E (2013) Warm Arctic, cold continents: a common pattern related to Arctic sea ice melt, snow advance, and extreme winter weather. Oceanography 26:150-160

Cohen J et al (2014) Recent Arctic amplification and extreme midlatitude weather. Nat Geosci 7:627-637

Cohen J et al (2020) Divergent consensuses on Arctic amplification influence on midlatitude severe winter weather. Nat Clim Change 10:20-29

Dai A, Luo D, Song M, Liu J (2019) Arctic amplification is caused by sea-ice loss under increasing CO2. Nat Commun 10:1-13

Dee DP et al (2011) The ERA-Interim reanalysis: configuration and performance of the data assimilation system. Q J R Meteorol Soc 137:553-597

Deser C, Tomas RA, Sun L (2015) The role of ocean-atmosphere coupling in the zonal-mean atmospheric response to Arctic sea ice loss. J Clim 28:2168-2186

Ding Q, Wallace JM, Battisti DS, Steig EJ, Gallant AJ, Kim HJ, Geng L (2014) Tropical forcing of the recent rapid Arctic warming in northeastern Canada and Greenland. Nature 509:209-212

Duchon CE (1979) Lanczos filtering in one and two dimensions. J Appl Meteorol 18:1016-1022

Fan SM, Harris LM, Horowitz LW (2015) Atmospheric energy transport to the Arctic 1979-2012. Tellus A Dyn Meteorol Oceanogr $67: 25482$

Francis JA, Vavrus SJ (2012) Evidence linking Arctic amplification to extreme weather in mid-latitudes. Geophys Res Lett 39:L06801

Ghatak D, Miller J (2013) Implications for Arctic amplification of changes in the strength of the water vapor feedback. J Geophys Res Atmos 118:7569-7578 
Graversen RG, Burtu M (2016) Arctic amplification enhanced by latent energy transport of atmospheric planetary waves. Q J R Meteorol Soc 142:2046-2054

Graversen RG, Wang M (2009) Polar amplification in a coupled climate model with locked albedo. Clim Dyn 33:629-643

Graversen RG, Mauritsen T, Tjernström M, Källén E, Svensson G (2008) Vertical structure of recent Arctic warming. Nature 541:53-56

Holland MM, Bitz CM (2003) Polar amplification of climate change in coupled models. Clim Dyn 21:221-232

Huang D, Dai A, Yang B, Yan P, Zhu J, Zhang Y (2019) Contributions of different combinations of the IPO and AMO to recent changes in winter East Asian jets. J Clim 32:1607-1626. https://doi.org/ 10.1175/JCLI-D-18-0218.1

Kug JS, Jin FF (2009) Left-hand rule for synoptic eddy feedback on low-frequency flow. Geophys Res Lett 36:L05709

Kug JS, Choi DH, Jin FF, Kwon WT, Ren HL (2010) Role of synoptic eddy feedback on polar climate responses to the anthropogenic forcing. Geophys Res Lett 37:L14704

Laîné A, Yoshimori M, Abe-Ouchi A (2016) Surface Arctic amplification factors in CMIP5 models: land and oceanic surfaces and seasonality. J Clim 29:3297-3316

Lambert $\mathrm{F}$ et al (2013) The role of mineral-dust aerosols in polar temperature amplification. Nat Clim Chang 3:487-491

Lee S (2014) A theory for polar amplification from a general circulation perspective. Asia Pac J Atmos Sci 50:31-43

Lee HJ et al (2017) Impact of poleward moisture transport from the North Pacific on the acceleration of sea ice loss in the Arctic since 2002. J Clim 30:6757-6769

Lin Z, Lu R (2005) Interannual meridional displacement of the East Asian upper-tropospheric jet stream in summer. Adv Atmos Sci 22:199-211

Lin Z, Lu R (2009) The ENSO's effect on eastern China rainfall in the following early summer. Adv Atmos Sci 26:333-342

Luo D, Xiao Y, Yao Y, Dai A, Simmonds I, Franzke CLE (2016) Impact of ural blocking on Winter Warm Arctic-Cold Eurasian Anomalies. Part I: blocking-induced amplification. J Clim 29:3925-3947

Luo D, Chen X, Dai A, Simmonds I (2018) Changes in atmospheric blocking circulations linked with winter arctic warming: a new perspective. J Clim 31:7661-7678

Meleshko VP, Johannessen OM, Baidin AV, Pavlova TV, Govorkova VA (2016) Arctic amplification: does it impact the polar jet stream? Tellus A Dyn Meteorol Oceanogr 68:32330

Miyakoda K, Gordon T, Caverly R, Stern W, Sirutis J, Bourke W (1983) Simulation of a blocking event in January 1977. Mon Weather Rev 111:846-869

Nakamura H, Wallace J (1993) Synoptic behavior of Baroclinic Eddies during the blocking onset. Mon Weather Rev 121:1892-1903

Pearson RG, Phillips SJ, Loranty MM, Beck PSA, Damoulas T, Knight SJ, Goetz SJ (2013) Shifts in Arctic vegetation and associated feedbacks under climate change. Nat Clim Chang 3:673-677

Pithan F, Mauritsen T (2014) Arctic amplification dominated by temperature feedbacks in contemporary climate models. Nat Geosci 7:181-184

Plumb RA (1985) On the three-dimensional propagation of stationary waves. J Atmos Sci 42:217-229

Plumb RA (1986) Three-dimensional propagation of transient quasigeo-strophic eddies and its relationship with the eddy forcing of the time-mean flow. J Atmos Sci 43:1657-1678

Ren X, Zhang Y, Xiang Y (2008) Connections between wintertime jet stream variability, oceanic surface heating, and transient eddy activity in the North Pacific. J Geophys Res 113:D21119

Screen JA, Simmonds I (2010) Increasing fall-winter energy loss from the Arctic Ocean and its role in Arctic temperature amplification. Geophys Res Lett 37:L16707
Screen JA, Deser C, Simmonds I (2012) Local and remote controls on observed Arctic warming. Geophys Res Lett 39:L10709

Sun L, Deser C, Tomas RA (2015) Mechanisms of stratospheric and tropospheric circulation response to projected Arctic sea ice loss. J Clim 28:7824-7845

Takaya K, Nakamura H (2001) A formulation of a phase-independent wave-activity flux for stationary and migratory quasigeostrophic eddies on a zonally varying basic flow. J Atmos Sci 58:608-627

Trenberth KE (1986) An assessment of the impact of transient eddies on the zonal flow during a blocking episode using localized Eliassen-Palm flux diagnostics. J Atoms Sci 43:2070-2087

Wu B, Su J, D’Arrigo R (2015) Patterns of Asian Winter climate variability and links to Arctic Sea Ice. J Clim 28:6841-6858

Xiang Y, Yang XQ (2012) The effect of transient eddy on interannual meridional displacement of summer East Asian subtropical jet. Adv Atmos Sci 29(3):484-492

Xiao D, Li J (2007) Spatial and temporal characteristics of the decadal abrupt changes of atmosphere-ocean system in 1970s. J Geophys Res 112:D24S22

Xiao C, Zhang Y (2015) Projected changes of wintertime synopticscale transient eddy activities in the East Asian eddy-driven jet from CMIP5 experiments. Geophys Res Lett 42:6008-6013

Xiao C, Zhang Y, Lofgren BM, Nie Y (2016) The concurrent variability of East Asian subtropical and polar-front jets and its implication for the winter climate anomaly in China. J Geophys Res Atmos 121:6787-6801

Xue D, Zhang Y (2017) Concurrent variations in the location and intensity of the Asian winter jet streams and the possible mechanism. Clim Dyn 49:1-16

Yang S, Webster PJ (1990) The Effect of summer tropical heating on the location and intensity of the extratropical westerly jet streams. J Geophys Res Atmos 951(D11):18705-18721

Yang S, Lau K-M, Kim K-M (2000) Characteristics of the East Asian winter climate associated with the westerly jet stream and ENSO. NASA/Goddard Space Flight Center Lab Atmos 15:1-28

Yang S, Lau K-M, Kim K-M (2002) Variations of the East Asian Jet stream and Asian-Pacific-American Winter climate anomalies. J Clim 15:306-325

Yoo C, Feldstein S, Lee S (2011) The impact of the Madden-Julian Oscillation trend on the Arctic amplification of surface air temperature during the 1979-2008 boreal winter. Geophys Res Lett 38:L24804

Yoo C, Lee S, Feldstein SB (2012) Arctic response to an MJO-Like tropical heating in an idealized GCM. J Atmos Sci 69:2379-2393

Zhang YC, Chen J (2017) Characterizing the winter concurrent variation patterns of the subtropical and polar-front jets over East Asia. J Meteor Res 31:160-170

Zhang YC, Huang DQ (2011) Has the East Asian westerly jet experienced a poleward displacement in recent decades? Adv Atmos Sci 28:1259-1265

Zhang X, He J, Zhang J, Polyakov I, Gerdes R, Inoue J, Wu P (2013) Enhanced poleward moisture transport and amplified northern high-latitude wetting trend. Nat Clim Chang 3:47-51

Zhao S, Ren HL, Zhou F, Gao L (2020) Role of Eddy heat feedback in modulating winter mean NAO-related thermodynamic structure. J Geophys Res Atmos. https://doi.org/10.1029/2019JD031990

Publisher's Note Springer Nature remains neutral with regard to jurisdictional claims in published maps and institutional affiliations. 